\title{
3D printing in the battle against COVID-19
}

\author{
Ayca Aydin ${ }^{1} \cdot$ Zeynep Demirtas $^{1} \cdot{\text { Merve } \text { Ok }^{1} \cdot \text { Huseyin Erkus }}^{1} \cdot$ Gizem Cebi $^{1} \cdot$ Ebru Uysal $^{1,2,3} \cdot$ Oguzhan Gunduz $^{3,4}$ (D) \\ Cem Bulent Ustundag ${ }^{1,3}$
}

Received: 1 November 2020 / Accepted: 12 January 2021 / Published online: 8 February 2021

(C) Qatar University and Springer Nature Switzerland AG 2021

\begin{abstract}
Coronavirus disease 2019 (COVID-19) that is SARS-CoV-2, previously called 2019-nCoV, is a kind of human infectious disease caused by severe acute respiratory syndrome coronavirus. Based on the prompt increase of human infection rate, COVID-19 outbreak was distinguished as a pandemic by the World Health Organization (WHO). By 2020, COVID-19 becomes a major health problem all around the world. Due to the battle against COVID-19, there are some adversities that are encountered with. The most significant difficulty is the lack of equipment for the COVID-19 battle. Lately, there is not sufficient personal protective equipment (PPE) for hospital workers on the front lines in this terrifying time. All around the world, hospitals are overwhelmed by the volume of patients and the lack of personal protective equipment including face masks, gloves, eye protection and clothing. In addition, the lack of nasal swabs, which are necessary components, that are used for testing is another issue that is being faced. There are a small number of respirators, which are emergency devices that help patients breathe for a short period of time. To overcome the limited number of equipment available, the foremost solution can be 3D printing that allows three-dimensional renderings to be realized as physical objects with the use of a printer and that revolutionized prototyping. Low-cost desktop 3D printers allow economical 3D models and guides but have less quality approvals. 3D printing is already well integrated into the process of COVID-19 battle by manufacturing the equipment that are convenient. The goals of this review are to explore the techniques of $3 \mathrm{D}$ printing for the equipment that are used for COVID-19 battle and evaluate the materials that are used for manufacturing and the manufactured equipment. Lastly, the advantages and disadvantages of $3 \mathrm{D}$ printing are figured out.
\end{abstract}

Keywords COVID-19 $\cdot$ SARS-CoV-2 $\cdot 3$ D printing $\cdot$ Biomaterials $\cdot$ Tissue engineering

\section{Introduction}

SARS-CoV-2, which has affected the whole world, first appeared in a market where seafood is sold in Wuhan, China, in December 2019. As of March 11, COVID-19

Oguzhan Gunduz

ucemogu@ucl.ac.uk

$\triangle$ Cem Bulent Ustundag

cbustundag@gmail.com

1 Department of Bioengineering, Faculty of Chemical and Metallurgical Engineering, Yildiz Technical University, 34210 Istanbul, Turkey

2 Vocational School of Health Care Services, Istanbul Yeni Yuzyil University, 34010 Istanbul, Turkey

3 Center for Nanotechnology and Biomaterials Application and Research (NBUAM), Marmara University, 34722 Istanbul, Turkey

4 Department of Metallurgical and Materials Engineering, Faculty of Technology, Marmara University, 34722 Istanbul, Turkey disease has been declared a pandemic by the World Health Organization [1]. Many people have lost their lives in the process that has passed since the day it emerged. According to the data of the World Health Organization, $79,673,754$ confirmed cases and 1,761,381 deaths (as of December 28) have occurred worldwide so far [2]. Since the disease can be transmitted from person to person, it can spread easily. The more contact, the higher the risk of contracting the disease. While the disease is highly transmitted through respiratory droplets, some studies show that the disease can be transmitted by other means [3].

Disease symptoms include lack of taste and smell, high fever, dry cough, shortness of breath, weakness, muscle and joint pain, sore throat and diarrhoea [4]. The most common of these are high fever, dry cough and malaise [5]. In the progressive course of the disease, pneumonia firstly and then multiple organ failure occur depending on the disease. Patients with severe lung damage are connected to respiratory support devices [6]. 
In studies conducted on patients, it has been determined that COVID-19 disease has no effect on gender and age, and the risk of transmission of SARS-CoV-2 to people of different races, genders, and ages is equal [3].

Currently, there is no definitive treatment method for COVID-19. With the measures taken, the rate of catching the disease is tried to be prevented. For this reason, personal protective equipment (PPE) is used. Certain parts of many protection equipment used within the scope of coronavirus measures, (masks, visors), parts of ventilator devices and some of the materials used for testing purposes are produced by $3 \mathrm{D}$ printers $[7,8]$. At the same time, 3D printing technology is promising for the treatment of organ damage caused by the disease.

$3 \mathrm{D}$ printing is a production method in which materials such as plastic or metal are stacked in layers to obtain 3D products [9]. It is also known as additive manufacturing (AM) or rapid prototyping [10]. Until now, this method has primarily been used to create prototypes in the engineering field [9]. It has applications in a variety of industries such as aviation, automotive, construction, marine and offshore and food [10]. In addition, it is widely used in the field of health [9]. In addition to these, it is a technology that enables many new applications. Basically for each application, production speed, print resolution and materials to be used should be considered. Depending on the International Organization for Standardization (ISO)/ American Society for Testing and Materials (ASTM) 52900: 2015 standard, the process in 3D printing applications is divided into seven basic categories. These are binder jetting, directed energy deposition, material extrusion, material jetting, powder bed fusion, sheet lamination and vat photopolymerization [11]. It makes possible mass customization of products compared to traditional printers [9]. This review will cover the $3 \mathrm{D}$ printing applications in the battle against COVID-19, a pandemic issue.

\section{COVID-19}

\subsection{The pathology of SARS-CoV-2}

SARS-CoV-2 is an enveloped single-stranded positive-sense RNA virus from the coronavirus family, is not segmented and is between 26 and $32 \mathrm{~kb}$ in length $[12,13]$. It has a nucleocapsid composed of genomic RNA and phosphorylated nucleoid capsid protein [13]. It comes from a common family with viruses that cause severe acute respiratory syndrome (SARS) and Middle East respiratory syndrome (MERS), which appeared in previous years [12] (Fig. 1).

One of the most significant building blocks of SARS-CoV2 is envelope spike (S) protein. The $\mathrm{S}$ protein mediates the binding of the virus to the receptor, which is called angiotensin-converting enzyme 2 (ACE-2), and has the ability

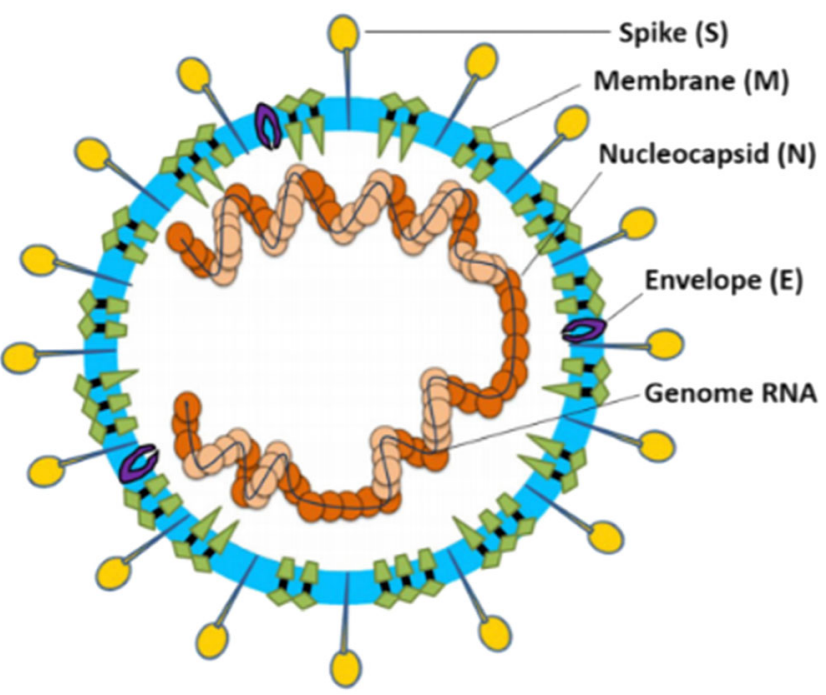

Fig. 1 Structure of coronavirus [13]

to perform membrane fusion. [4]. The areas in which this receptor is expressed are the cell entry sites for SARS-CoV2 , predominantly expressed in the pulmonary alveolar, heart, kidney and intestine $[4,14]$.

\subsection{Organ damages caused by COVID-19}

After the coronavirus enters the body, it can damage many organs. Although the permanence of these damages has not been proven yet, the duration of the disease varies according to the size of the damage.

Researches have indicated that coronavirus usually enters the body through respiration and causes pneumonia by damaging the lungs [6]. In the examinations performed on the lungs of patients who tested positive for COVID-19, ground-glass opacities and consolidation were detected in the lungs of some patients who underwent chest CT scans [15]. More studies are required to understand whether this condition is permanent in individuals who survive from the disease.

The liver is also affected by the disease. Abnormal levels of alanine transaminase (ALT) and aspartate transaminase (AST) have been detected in the blood of some of the patients infected with SARS-CoV-2. Detection of these enzymes at a high rate indicates that the liver has been damaged. COVID-19induced liver damage is thought to be caused by druginduced toxicity and systemic inflammation caused by hypoxia associated with pneumonia or cytokine storm. It is also thought that the virus can directly infect liver cells, thanks to the ACE-2 proteins found in the liver [16].

Studies about the gastrointestinal system suggested that the coronavirus could affect this system as well. The detection of SARS-CoV-2 in the stool of a sick individual by Holsue et al. suggested that the virus would also affect the gastrointestinal system [13]. Other studies have demonstrated that ACE-2 is expressed in stomach, duodenal and rectal epithelial cells. In a 
study conducted in the UK, it was found that the interaction between SARS-CoV-2 and ACE-2 disrupted the function of ACE-2 and caused diarrhoea. For patients with digestive diseases or potential faecal microbiota transplant donors, the ability of the virus to be linked through the digestive system is of concern [16].

Studies on patients diagnosed with COVID-19 showed that the virus also had an effect on the cardiovascular system. Cardiovascular comorbidities were more common in individuals with severe disease. According to data from the Chinese National Health Commission, $17 \%$ of the people who got the disease had coronary heart disease. In a study conducted on 138 patients in Wuhan, China, myocardial damage was detected in $22 \%$ of the patients [17]. In a study conducted on patients in North America, Europe, and Asia, it was found that patients who died from COVID-19 had a prevalence of coronary artery disease, heart failure and cardiac arrhythmia [14]. Cardiovascular disorders caused by COVID-19 can vary depending on age, immune system function, presence of ACE-2 protein and previous cardiovascular disease [17].

Neurological problems occur in about $50 \%$ of individuals diagnosed with COVID-19. More than 300 studies conducted around the world have shown that COVID-19 patients develop mild symptoms such as headache, loss of smell and tingling. These symptoms can progress and cause severe neurological damage: paralysis, inability to speak and nervous seizures [18]. According to an article published in the journal Brain, patients diagnosed with COVID-19 have experienced hallucinations, paralysis and delirium. Studies were carried out on 43 patients in London. As a result of the studies, 10 patients were diagnosed with delirium, 12 patients with brain inflammation and 8 patients with nerve damage. In addition, paralysis and hallucinations were observed in some patients [19]. These damages in the brain are thought to be caused by low oxygen saturation or cytokine storm. When the autopsy of individuals who died as a result of COVID-19 in Italy was examined, viral particles were detected in the endothelial cells covering the blood vessels of the brain. This strengthened the possibility that the virus could bind directly to brain cells. Scientists have recently suspected that the virus actually causes respiratory failure and death by damaging the brain stem rather than through the lungs [18].

Another organ thought to cause damage from COVID-19 is the kidney. High levels of protein in the urine and abnormal levels in blood values are among the indicators of kidney damage. Moderate or severe kidney damage has occurred in $30 \%$ of patients diagnosed with COVID-19 in China and New York. While acute kidney damage is observed in some patients, in some patients, the damage may be severe enough to require dialysis [20]. According to the data of the American Nephrology Association, 10 to $50 \%$ of patients in intensive care have kidney failure at a level that requires dialysis. Since the beginning of the pandemic in Mount Sinai,
$46 \%$ of patients diagnosed with COVID-19 have been diagnosed with acute kidney disease, and many patients had no history of kidney disease [21]. SARS-CoV-2 can form clots that can impair the function of the kidney by occluding the blood vessels in the kidney. Thanks to the ACE-2 proteins found in kidney cells, it is thought that the virus can bind to these cells and damage the kidney. Concurrently, observing abnormally low oxygen levels in the blood due to pneumonia that occurs with the entry of the virus into the body can also cause kidney damage. Cytokine storm is observed as another possibility. Severe inflammation that can occur in the body due to severe cytokine influx can destroy healthy tissues in the kidney [20].

\section{3D printing technology}

The $3 \mathrm{D}$ printing method, known as the layered production (AM) method, is based on the principle of layered production of various materials such as powders, metal, living cells, plastic, liquids and ceramics. This method generates various and complex 3D geometries using a computer-aided design (CAD) model or computed tomography (CT) scanning [22, $23]$. With the $3 \mathrm{D}$ printing method, it is possible to create personalized organ and scaffold models and quickly produce and print defective areas directly. In this way, 3D printing technology offers new possibilities in the field of medicine to solve donor problems and create tissue or organ models $[22,24]$. Due to the low production costs of 3D printers that have fast and simple system, 3D printing method has recently gained great importance in the fields of medical equipment, implant material and cell printing [9]. The printing process includes several steps such as design, software workflow, material checks, printing, finishing, process validation and testing. First, the desired printing model is designed using a 3D CAD model. This CAD model is then converted into a file containing instructions on how the printer will create the product and sent to the printer. The most significant parameter of the designed product is the material used to create the product. It is crucial that the material used is selected according to the desired properties. The instructions are ready to be delivered to the printer as a printable software file (most commonly GCode or AMF). After printing the product, post-processing steps and some testing can be applied to the product [25]. The main methods of 3D printing technology are shown in Table 1 below.

\subsection{D printing methods}

\subsubsection{Fused deposition modelling}

In the fused deposition modelling (FDM) method, printing layers of product thermoplastic polymer filament are used. 


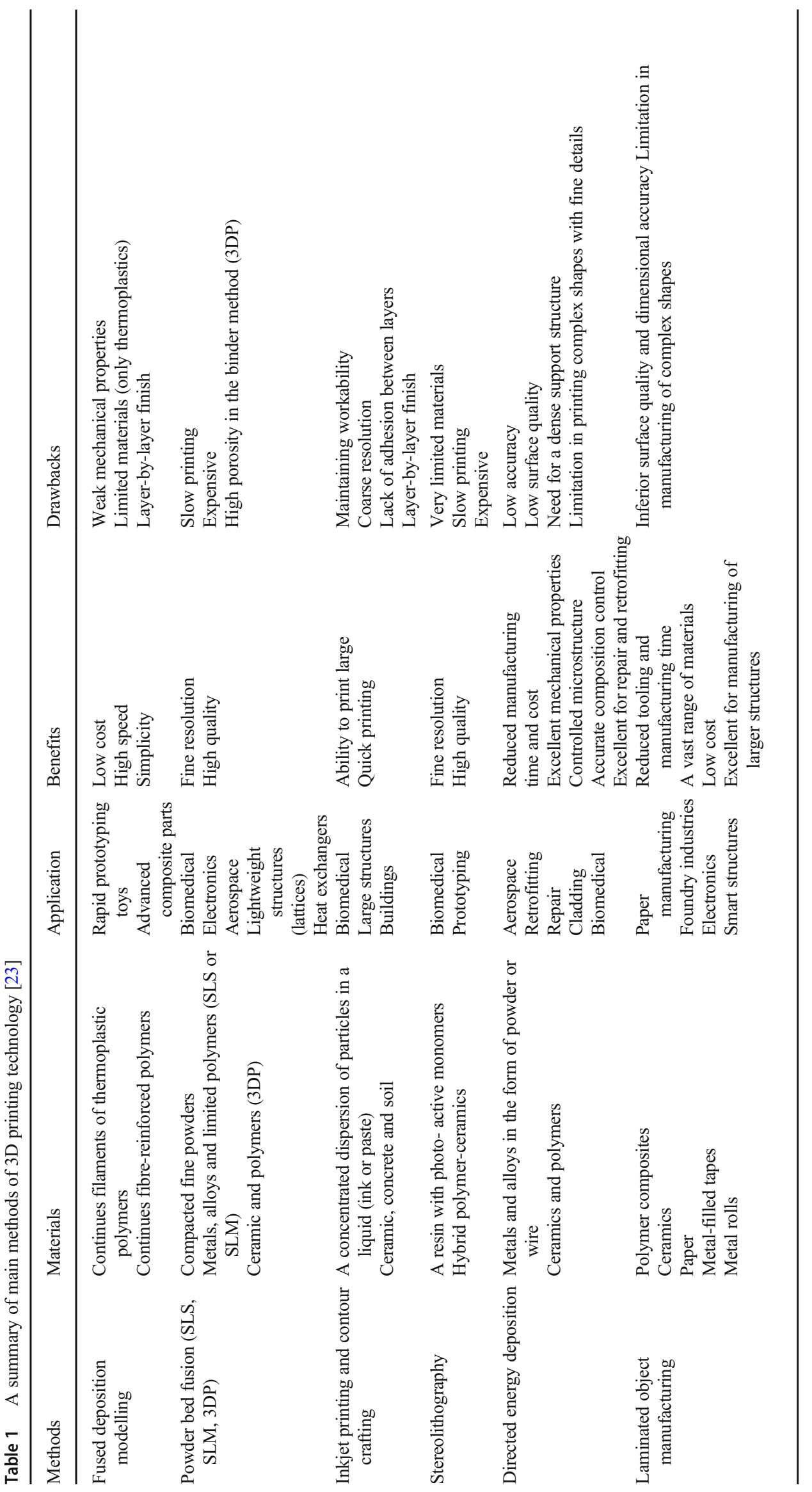


The filament is firstly heated until a semi-liquid state is reached at the nozzle and then extruded onto previously printed layers [23]. This method is inexpensive and easy to use and install and also has a low material cost. It can be printed by FDM printers that are using a variety of materials such as polylactic acid (PLA), ABS, TPE/TPU, soluble material, nylon and polypropylene [24].

\subsubsection{Binder jetting}

In this rapid and additive manufacturing method, a liquid binder is selectively deposited to coalesce the powder particles. In binder jetting process, a lot of materials including sands, polymers, metals, hybrid and ceramics can print. Moreover, the binder jetting process is fast, simple, inexpensive and capable of printing large products [26].

\subsubsection{Directed energy deposition}

Directed energy deposition (DED) method is mainly used in the production of high-performance super alloys [23]. This method is used for printing polymers, ceramics, metals and metal-based hybrids [26].

\subsubsection{Material jetting}

In material jetting, the material is selected and deposited drop by drop. This process is based on the dispensing of photosensitive material droplets by a printhead, building a part layered manufacturing using the ultraviolet (UV) light. A multimaterial print is available with materials such as biologicals, polymers, composites, hybrids and ceramics [26].

\subsubsection{Powder bed additive manufacturing (PBF)}

This $3 \mathrm{D}$ printing process examples are selective laser sintering (SLS), electron beam melting (BM) and selective heat sintering (SHS) printing techniques. In this method, the material powder is melted using an electron beam or laser. Various materials are used such as metals, hybrids, ceramics, polymers and composites [26].

\subsubsection{Sheet lamination technology}

In this method, sheets of material are bonded together to produce a portion of a product. Ultrasound additive manufacturing (UAM) and laminated object manufacturing (LOM) are examples of this process [26].

\subsubsection{Vat polymerization process}

Vat polymerization technique is generally based on the principle of using a light, ultraviolet (UV) or laser to the curing of photopolymers. The examples of this process are digital light processing (DLP) and stereolithography (SLA). A highquality product with good details is possible by the photopolymerization method [26].

\subsubsection{Inkjet printing and contour crafting}

According to digital instructions, inkjet printing technique uses electromagnetic, piezoelectric or thermal technology to depositing droplets of "ink" onto a substrate. Heated printhead generates air bubbles that collapse, generating pressure pulses to ejecting drops from nozzles [27]. This method, which is efficient and fast, creates flexible complex structures [23].

\subsubsection{Other methods}

3D printing also has methods such as high-resolution 3D printing, 3D printing using reversible addition-fragmentation chain transfer (RAFT) photopolymerization and 4D printing. In this $3 \mathrm{D}$ printing method that works with high-energy ultraviolet (UV) light, liquid resins are transformed into solid objects with high speed and high resolution. This method provides many advantages such as lower cost, high biocompatibility and deeper penetration [28]. The alternative method is the photoredox-catalysed RAFT polymerization method using different reagents. RAFT polymerization is activated by a photoredox catalyst through a light-induced transfer of electron or energy between the RAFT agent and the catalyst [29]. $4 \mathrm{D}$ printing is also the creation of three-dimensional structures that have the ability to adopt different shapes when exposed to various environmental stimuli with smart materials. This method offers numerous advantages such as low cost, short time period, flexibility, versatility and low margin of error [30]. In 4D bio-printing method, after living cellular structures are printed, cells can continue to develop and form structures similar to natural tissue [29]. Although there are certain limits to these methods, they could create new opportunities of producing 3D printed materials with vivid characters, but more systematic studies are needed.

\subsection{D printing technology applications in manufacturing}

3D printing is frequently used in many areas such as aerospace industry, construction, architecture, building, medicine, electricity, automotive industry, food, textile, fashion industry, healthcare and medical industry. In the healthcare and medical industry, 3D printing technology has several advantages:

- With 3D printing technology, the natural structure of the skin is produced at a lower cost.

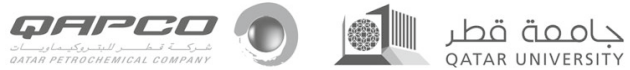


- By printing drugs with 3D printing technology, drug efficiency can be increased; size reduction, required dosage and accurate control of drugs are provided.

- With 3D printing, the function of organs and tissues can be improved, replaced or maintained.

- 3D printing technology focuses on producing, improving or preserving the function of the bone or cartilage as a result of damage from trauma or disease.

- Organ failure that is caused by accidents, illness and birth defects can also be printed by 3D printing technology.

- 3D printing technologies can create controllable models of cancer tissues and have the potential to accelerate great cancer research [26].

\section{Materials}

\subsection{Materials used in 3D printing for COVID-19}

Considering personalized medicine, which is an upcoming major area, 3D printing is the perfect technology. A wide variety of biomaterials such as polymeric biomaterials, hydrogel, ceramicbased and composite have been used and developed as inks for creating 3D structures with a wide range of size and stiffness [31]. There are plentiful printable materials with great specifications for using in external applications, but biomaterials must have specific features for being implantable. Printable biomaterials must be biocompatible, have suitable mechanical properties, have acceptable degradation kinetics and demonstrate tissue biomimicry, and also their degradation by-products must be safe for the physiological conditions and interactions with the body. In addition, FDA approval is another major factor for the biomaterial used in $3 \mathrm{D}$ printing $[32,33]$.

In the battle against COVID-19, there are three approaches: preventing the virus from entering the cell, preventing the virus proliferation in the cell and preventing the body's overreaction to the virus. Studies continue based on these approaches all around the world, but as is known, organ damage from COVID-19 may occur. Tissue engineering can be used to treat organ damage caused by COVID-19, but the applications of 3D printing in the field of tissue engineering are limited because of the biomaterials that are used in this technology. Despite the existence of limitations, there are a variety of materials such as protein-derived biomaterials like albumin, fibronectin, collagen, hyaluronic acid and this kind of materials that also provide an appropriate environment for cell growth [34]. Proteins, natural polymers, are used widely because of their beneficial characteristics like biodegradability, biocompatibility, and abundant availability [35]. Polymeric materials have important advantages such as low cost, high availability, effortlessness in design and synthesis and unique mechanical properties for organ scaffold synthesis and support, but there polymers that provide biocompatibility are not enough [36]. PLA, PVA and
ABS can be given as examples. Synthetic and natural polymer combinations are also used for scaffold designing in tissue engineering for organ damage [36].

SARS-CoV-2 infection can be divided into three levels. In stage 1 , there is an asymptomatic incubation period, while stage 2 and 3 are non-severe and severe symptomatic periods, respectively [37]. Therefore, when the immune response of the host is insufficient, devastation of the affected tissue will occur, especially organs like the kidney and intestine where ACE-2 expression is high. As a result of this destruction, the damaged cells stimulate the initiation of inflammation in the lungs. The key to life-threatening respiratory disorders at the severe stage is lung inflammation, so the focus at this point should be about pushing down inflammation and managing symptoms [38]. 3D printing can be used for producing simple design, proper, inexpensive, structured and tailored drug delivery systems for this purpose. HPMC, poly(acrylic acid), cellulose acetate, and polyvinyl alcohol (PVA) are the examples of the materials used in 3D for drug delivery systems [39].

Although there are plenty of studies that determine the treatment of COVID-19, another significant point about this issue is preventing the spread of infection. In accordance with this purpose, the lack of equipment is a significant limitation in the battle against COVID-19. Consequently, there is an increasing demand for medical devices, visualization aids and personal protective equipment (PPE) such as gloves, face masks and face shields, respirators and their filters, which are used by hospital staff. For the manufacturing of PPEs like face mask, polylactic acid (PLA) polymer can be used [40]. In addition, arthroplasty helmets are redesigned to use as a PPE in a study by using silicone [41]. Lastly, 3D printing can also be used for the fabrication of temporary emergency dwellings to isolate people under quarantine [42].

\subsection{Which types of equipment that are printed by 3D for COVID-19}

Since the COVID-19 is a pandemic issue, to detect SARS-CoV2 infection during early stages, the nasopharyngeal (NP) swab is an urgent equipment to collect nasal epithelial mucosa for testing. Currently, the demand for the nasopharyngeal swabs is unpredictably increasing, and with the help of 3D printing, immediate mass production for new swabs can be made [43].

Medical face shields have been become a trendy PPE to fabricate especially for healthcare workers. Face/eye protection demands more attention for the issues associated with severe infectious agents since the face is the most commonly exposed part of the body. Although wearing a surgical face mask might ensure protection from a distance between healthcare workers and patients who are diagnosed with COVID-19, additional PPE would be a necessity. 3D printing is sufficient to overcome the high demand for PPE. Because of this reason, different concept designs for face shield products are produced by additive 
manufacturing. In the additive manufacturing process for face shields, biodegradable thermoplastic polymer/polylactic acid (PLA)-based material is used [44].

Currently, there are two types of focus in PPE, which are barrier PPE and filtering PPE. Since COVID-19 outbreak happened so quickly, the whole world needs both types immediately. Production methods that allow rapid shift manufacturing to PPE and related supplies can be used; however, the supply chain system is not prepared completely. Since 3D printing entails limited or no modification for a replacement from one product to making another, it is an elegant technology to do this. In the homemade 3D-printed face mask models with an integrated filter medium, 3D component ensures an airproof atmosphere between the airway of the user and the filter material [45].

According to WHO, one in six COVID-19 patients is suffering from difficulty breathing. By this reason, ventilator that supplies sufficient oxygen into the patient's lungs and that removes the carbon dioxide support may be required. A promising development about 3D-printed ventilators has taken place in Spain. Although it cannot be described as a ventilator but an emergency unit, it can be beneficial for patients who are suffering from breathing difficulty, but cannot be for the serious cases [46] (Fig. 2).

\section{The role of 3D printing and its applications in COVID-19}

During the COVID-19 outbreak, more than 100 different 3D printable PPE designs have been developed [47].This systematic review is written by benefiting different Internet libraries. These libraries were ScienceDirect, PubMed, Google Scholar, and Google News. The words "3D print", "COVID-19" and "materials" were used during searches for the studies examined in this section. The search year range in all libraries is set to cover November 2019 and beyond, the date of the first appearance of the disease. Moreover, 195 results were found in ScienceDirect and 119 results in PubMed. Furthermore, 7530 results were found in Google Scholar, but there are repeated results in these results. The article is selected by the usage of the 3D printing method and whether the printed material was used in the fight against COVID-19. Articles that do not comply with these terms were not included in the review. Related researches are described in detail below in subheadings.

\subsection{Personal protective equipment}

Minimizing the transmission of the virus from person to person depends on the effective use of personal protective equipment such as face and respirator masks, air-purifying respirators and face shields [7].
Medical staffs are working with great pressure increasing day by day since the alarming increase in the number of COVID-19 cases, not to mention virus mutations. One of the most important issues is the required number of medical equipment stock such as ventilators or face shields is inadequate because of the high demand and general disruptions to the global supply chain [48]. Protection of healthcare workers is a significant issue, especially during the treatment of COVID-19 patients, since their risk of being exposed to disease is too high. Healthcare workers are obliged to wear a mask with high filtering properties and a face shield while working. For this subject, efforts have been started to produce new ones instead of personal protective equipment that are inadequate (Table 2). To provide more technical notes, there is an article reporting the entire digital workflow of Charlotte and Dave connectors to breathing devices [59]. The NIH 3D Print Exchange portal, where various protection equipment are also designed, models to be 3D printed can be discovered and created, which were launched by the National Institute of Health [8].

\subsubsection{Face masks}

Face masks are one of the leading personal protective equipment. Masks that are named as surgical masks cover the nose and mouth, but do not fit the face properly and are loose. A face mask that provides a one-sided protection also ensures to prevent outcoming body fluid and to hold germs. Yet, respirators fit perfectly and do not leak, and their filter retention rate is very high. Respirators without valves provide double-sided protection, since they filter the incoming and outgoing air. However, ventilators provide one-sided protection, although they facilitate breathing of air and reduce moisture accumulation. In addition, there are 3 types of respirator masks: disposable, half face and full face. Various studies have been carried out to provide high protection and to increase the comfort of usage [55] (Figs. 3 and 4).

The 3D-printed mask designed by Tomas et al. consists of 3 reusable parts, which are mask base, filter grill and filter insert [49]. As PLA does not harm in contact with the skin, these components are obtained by using polylactic acid (PLA). In addition to harmlessness, PLA is inexpensive and easy to print and does not require high temperatures to be shaped. Ultimaker S3 printer was used to print the mask parts. Mask straps are produced by using phlebotomy straps, which can be reused or disposed of. The disposable filter is placed between filter grill and filter insert. As a filter, nanosized Cummins filters with the ability to filter over $95 \%$ are used $[49,50]$.

The aim of the project designed by Kvatthro is to produce a mask with a reusable and replaceable HEPA filter with 3D printing technique to enhance its user and environmental 


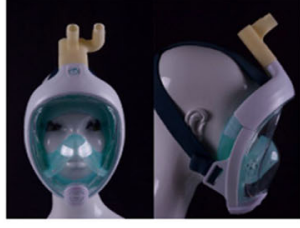

\section{Medical devices}

Ventilator valves

- Mask connectors for CPAP and BIPAP
- Emergency respiration device

- Emergency respiration device

- Non-invasive PEEP mask

3D-printed Charlotte ralre

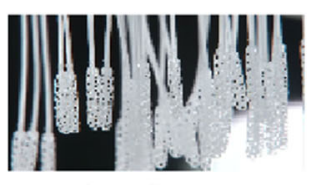

Testing devices

- Nasopharyngeal (NP) swabs

3D-printed NP swabs

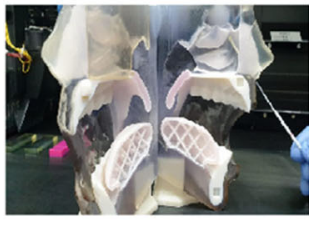

Training and visualization aids

- Medical manikins

- Bio-models

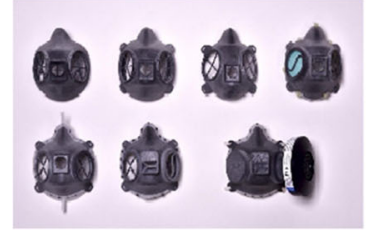

3D-printed respirators

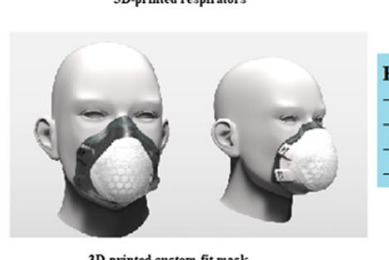

Personal accessories

- Face masks

Mask fitters

Mask adjusters

Door openers

Fig. 2 Equipment that are printed by 3D for COVID-19 [40]

protection. In this study, the PLA filament was preferred for the mask to be more compatible with each individual. It also has good sealing and high efficiency. This mask is highly advantageous since the plastic part of the mask can be reshaped using both microwave and hot water to ensure a better fit on the user's face [52, 53].

In the Lowell Makes' mask 3D-printed design, a design that filters can be put into the masks, mask straps are flexible and adjustable, and PLA and polyethylene terephthalate glycol (PETG) are ideal for printing these types of masks [53, 54].

Another significant system, powered air-purifying respirator (PAPR), is a system that provides filtered air, containing filters with a filtration rate of $95 \%$ or higher. Thus, it provides superior protection. Erickson et al. developed a helmet modification system with $3 \mathrm{D}$ printing. For this purpose, a new
Table 2 Personal protective equipment produced by $3 \mathrm{D}$ printing

\begin{tabular}{|c|c|c|c|c|}
\hline Producer & Materials & Purposes & Method & References \\
\hline \multicolumn{5}{|l|}{ Face mask } \\
\hline $\begin{array}{l}\text { Thomas } \\
\text { et al. }\end{array}$ & PLA & Customized mask production & FDM & {$[48]$} \\
\hline Kvatthro & PLA & Customized mask production & FDM/microwave & {$[49,50]$} \\
\hline $\begin{array}{l}\text { Lowell } \\
\quad \text { Makes }\end{array}$ & PLA/PETG & Flexible and adjustable strap & FDM & {$[50,51]$} \\
\hline $\begin{array}{l}\text { Erickson } \\
\quad \text { et al. }\end{array}$ & $\mathrm{N} / \mathrm{A}$ & Converting Flyte helmets to PPE & FDM & {$[52]$} \\
\hline $\begin{array}{l}\text { Swennen } \\
\text { et al. }\end{array}$ & PLA & $\begin{array}{l}\text { To produce a perfect fit mask with } 3 \mathrm{D} \text { face } \\
\text { scanning }\end{array}$ & FDM & {$[53]$} \\
\hline $\begin{array}{l}\text { Agarwal } \\
\text { et al. }\end{array}$ & PLA & $\begin{array}{l}\text { Comfortable breathing and preventing the } \\
\text { formation of fog in glasses }\end{array}$ & FDM & {$[54]$} \\
\hline $\begin{array}{l}\text { Copper } 3 D \\
\quad \text { mask } \\
\text { Face shields }\end{array}$ & PLA/copper & $\begin{array}{l}\text { To produce antibacterial copper } \\
\text { nanoparticle masks }\end{array}$ & N/A & {$[55]$} \\
\hline Tino et al. & PLA & Producing suitable face shields & FDM & {$[56]$} \\
\hline $\begin{array}{l}\text { Mueller } \\
\text { et al. }\end{array}$ & PLA/PETG & Obtaining more durable face shields & FDM & {$[57]$} \\
\hline \multicolumn{5}{|c|}{ Auxiliary accessories } \\
\hline $\begin{array}{l}\text { Manero and } \\
\text { friends }\end{array}$ & PLA & To facilitate the use of masks & FDM & {$[58]$} \\
\hline
\end{tabular}


Fig. 3 Respirator types: a disposable, $\mathbf{b}$ half face, and $\mathbf{c}$ full face [55]

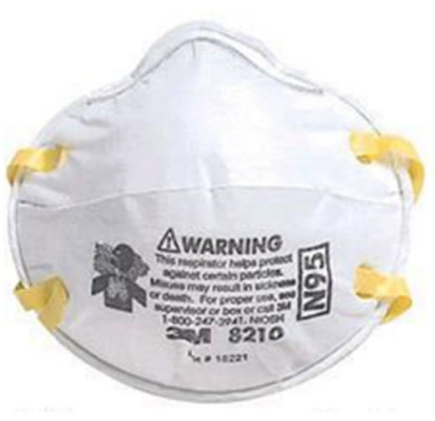

a

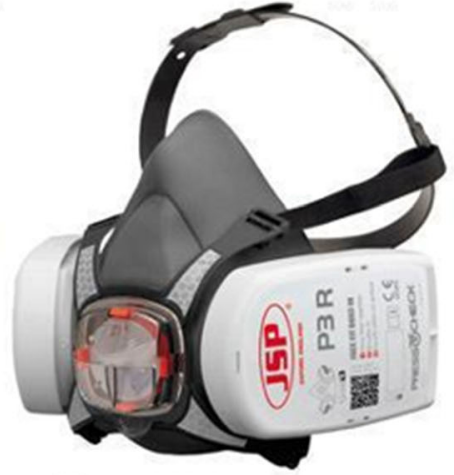

b

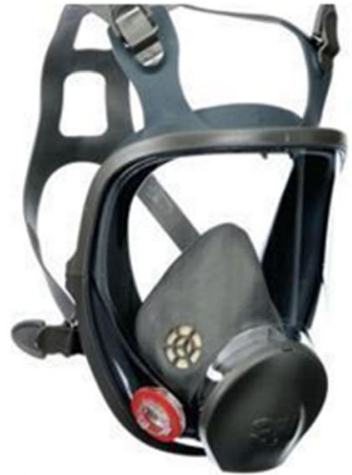

C manifold design that is placed on the fan and creates a sealed air that goes to the filter was produced. The manifold design is 3D printed using durable materials. A 2-port optimized design for an adequate approach was formed to enable the production of 3D-printed designs and the most ideal manifold. Thus, the Stryker Flyte helmet has been modified to create a design that will filter the air entering the helmet in the best way [41].

In addition, face masks printed by $3 \mathrm{D}$ printers can be custom-made by using face scanning programs. The image obtained with the face scanning program was designed with the $3 \mathrm{D}$ modelling program and masks were produced in these dimensions. This mask has two reusable parts (3D face mask and filter membrane support) and two non-reusable parts (head fixing tape and filter membrane). In this project, the custom-made face mask is produced with the additive production of two reusable components, and the disinfection of these components can be provided with antimicrobial solutions. For the filter membrane, which is one of the non-reusable components, blown polypropylene and Velcro tape were used as the head fixing band [60].

Agarwal et al., on the other hand, determined the problems of masks' inability to provide proper air circulation, the formation of vapour in the glasses, the inability to prevent the passage of particles adequately and the masks to be disposable and carried out studies to solve these problems. For this purpose, using the 3D method, the mask was produced by using PLA, which is a more durable and biodegradable material than surgical masks. In addition, the mask is lightweight and allows comfortable breathing due to its valves, which prevent vapour formation in glasses. At the same time, this mask can be shaped according to the facial anatomy of the user [56].

Copper 3D mask has been developed since there are deficiencies in the design of surgical masks and the existing surgical masks do not create a complete barrier against microbes. Copper 3D mask is produced by printing a flat piece from PLA filament and is biocompatible. Copper nanocomposite was loaded to gain antimicrobial properties and can be recycled, which is considered its positive speciality. This mask can inactivate viruses like SARS virus and H1N1 and has an antibacterial effect against many bacteria [51].

In addition, although the filters of reusable 3D-printed masks can be changed, the parts outside the filter also need to be disinfected [61]. For this reason, selection of a suitable disinfecting product is an important issue to produce reusable 3D-printed masks. A variety of disinfection products can be used, from alcohol to quaternary ammonium compounds. However, the product to be used should be selected in accordance with the mask material and printing technique to prevent any damage for the material.
Fig. 4 Respirator types: a with valve and $\mathbf{b}$ without valve [55]

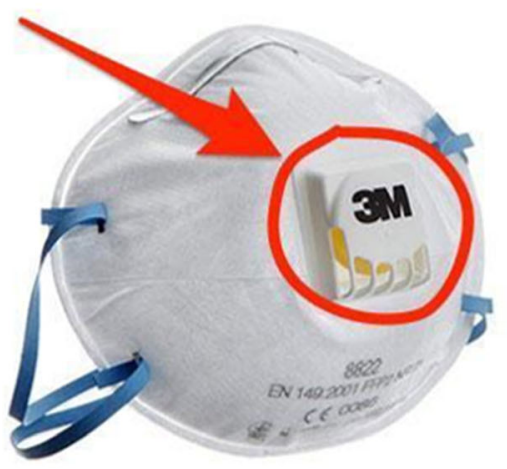

a

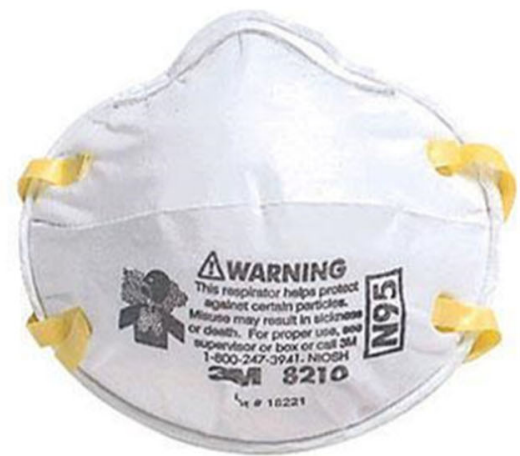

b 


\subsubsection{Face shields}

Protective face shields are simple devices that completely protect the face, including eyes, nose and mouth. Face shields consist of a cap that can be printed with $3 \mathrm{D}$ printers and a transparent layer attached to this cap. Considering its plain design, it is accessible to print with $3 \mathrm{D}$ devices. In addition, due to PPE limitation during the pandemic process, Prusa Research and some companies shared their face visor designs to be printed with a $3 \mathrm{D}$ printer for free [57].

Tino et al. used PLA filaments in their 3D printing design. Velcro strips, adhesive foam and transparent film are required to complete the shields. To make a face shield, it must first be digitally designed. Then, printer and filament settings such as nozzle diameter, height, horizontal and vertical position and material type and density are formed, and the title is printed. Finally, using the necessary materials, the transparent plate is mounted on the printed hood [58].

In addition, synthetic polymers such as polycarbonate, polyester and polyvinyl chloride are often used in making face shields due to their transparent, lightweight and easy-to-print characteristics with 3D printers [62].

PLA and polyethylene terephthalate glycol (PETG) were used in the face shield studies with 3D printers by Mueller et al. PLA is thermoplastic and known to be environmentally friendly due to the resources it produced and can be easily shaped. It can be printed at temperatures between $190{ }^{\circ} \mathrm{C}$ and $220^{\circ} \mathrm{C}$. However, it is not resistant to temperature, not mechanically strong, and not food safe and bacteria can easily reproduce during the process. PETG is more resistant to temperature and outdoor weather conditions and is a food-safe polymer. Considering these properties, PETG is used instead of PLA for face shields. Nonetheless, it must be sterilized before using [63].

During the process of printing face shields, the printing convenience and printing time of the polymer used should be considered. Moreover, with only a face shield as a protection, an individual is inadequately protected against the virus, so it is insufficient without at least a face mask.

\subsection{Auxiliary accessories}

Manero and his friends have made accessories that facilitate the use of masks using 3D devices [64]. These accessories are ear savers or mask extenders that increase mask wearing comfort. Polylactic thermoplastic was used for the mask extender and was printed with a 3D desktop-type font. These accessories can be made of many different materials and production can be carried out quickly due to their easy design. Mueller and his colleagues also worked on surgical mask straps [63]. Since accessories are easy to print and design, there are many computer-aided designs (CADs) that can be printed quickly with $3 \mathrm{D}$ devices (Fig. 5).

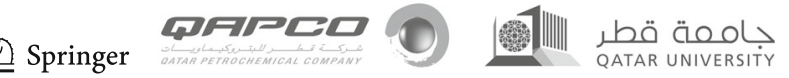

\subsection{Diagnostic tools}

\subsubsection{Swabs}

Millions of people around the world have been diagnosed with COVID-19. The diagnosis for SARS-CoV-2 consists of three stages: sample collection, nucleic acid extraction and reverse transcriptase PCR (RT-PCR) [65]. The World Health Organization (WHO) and the U.S. Center for Disease Control and Prevention (CDC) recommend nasopharyngeal (NP) swabs as the most ideal diagnostic example for COVID-19 [66]. Nasopharyngeal specimens are collected with NP swabs that are FDA Class 1 medical devices, $15 \mathrm{~cm}$ long and 2-3 $\mathrm{mm}$ in diameter, designed to collect secretion from the nasopharynx [43]. The head part of the rod is called the herd and consists of filaments or tubers that provide the collection. The swab is placed in the nasopharynx and poured several times to collect material. After this process, it is placed in a bottle, and the head part is separated from the breaking point on the rod. The bottle is sealed and sent for testing [43, $66]$.

The increasing number of diagnosed people steadily and the need for more tests to distinguish the diseased ones increase the need of NP swabs. Although swab manufacture was tried to increase to meet the need, adequate production could not be achieved during the pandemic period with existing production methods. The inadequate production encouraged researchers and engineers to develop effective methods that can allow them to manufacture convenient and abundant swabs (Fig. 6). As a result of these studies, many researchers have stated that swabs can be produced in the

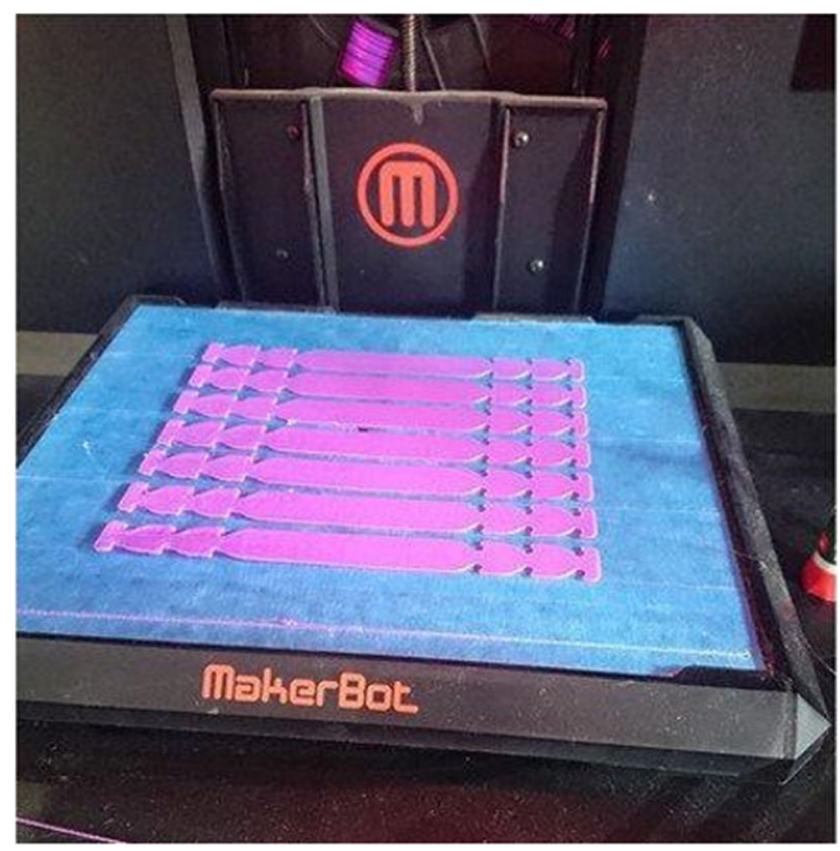

Fig. 5 Mask extender with 3D printing [64] 
Fig. 6 3D-printed swabs

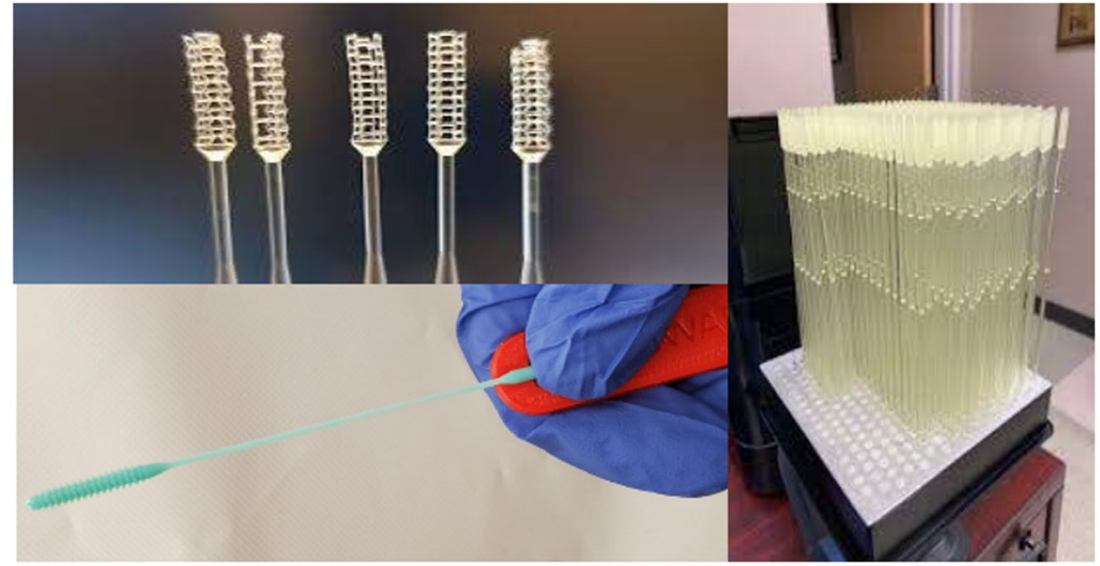

required quantities and specifications with the help of a $3 \mathrm{D}$ printer (Table 3).

It is concluded by researchers that with $3 \mathrm{D}$ printing, swabs can be easily and quickly produced in the hospital and laboratory environment in the appropriate quantity and format. Likewise, several swabs have been designed that can be easily produced by $3 \mathrm{D}$ printing. Williams et al. compared 3D-printed swabs to standard swabs using selective laser sintering technology. In the study, the feasibility and acceptability of 3Dprinted swabs for collecting samples for the SARS-CoV-2 test were reported [69]. Starosolski et al., however, designed more flexible paediatric nasopharyngeal swabs, stating that the standard or 3D care swaps used are not applicable for paediatric use. Maxillofacial CT scans of 1-3-year-olds were used during the designing stage [67]. COX and KOEPSELL, on the other hand, printed a $15-\mathrm{cm}$-long swap consisting of $0.5-\mathrm{mm}$ thick discs with 1-mm spacing on a filament-based printer that they designed. In a clinical study with commercial swabs, 2 patients were positively identified with 3D-printed swabs and 2 patients with standard swabs, which is an example of how 3D-printed swabs can be used instead of normal swabs [68]. In a joint study conducted by teams from the USF Health
Radiology and Northwell Health System, swabs proper for 3D printing were designed. Moreover, 324-380 swabs could be printed in 10-11 h using form $2 \mathrm{D}$ and form $3 \mathrm{D}$ printers. Clinical studies have found that these swabs have a $94 \%$ similarity to standard swabs [70]. Gallup et al. made an opensource design that includes swabs produced with a short handle with SLA printers. The swab holder is manufactured with FFF-type 3D printers. Mechanical verification test results have shown that these swabs can withstand greater forces in clinical use. In addition, this design and printing process as a result of significant time and cost savings can be achieved [71]. A team from the University of Wolverhampton has designed a 3D-printed nasal swab that can reduce the pain patients experience when removing a swab from their nose. This swab has a design that will better fit the patient's nasal cavity by adjusting itself. The 3D-printed stick inserted into the nose will shrink as it travels through the nasal cavity, causing less stress in the tissues [72].

Callahan et al. have done extensive preclinical work on 3Dprinted swabs. Twenty-four companies, laboratories and individuals received 160 swab designs and 48 materials as a result of their 4-step examinations on the high-speed production that
Table 3 Diagnostic tools generated by $3 \mathrm{D}$ printing

\begin{tabular}{|c|c|c|c|c|}
\hline \multicolumn{5}{|l|}{ Diagnostic tools } \\
\hline Producer & Materials & Purposes & Method & References \\
\hline \multicolumn{5}{|l|}{ Swabs } \\
\hline William et al. & Nylon 12 & To collect samples for PCR testing & SLS & {$[65]$} \\
\hline Starosolski et al. & N/A & Swab production for children & N/A & {$[66]$} \\
\hline $\begin{array}{l}\text { Cox and } \\
\text { Koepsell }\end{array}$ & PETG & $\begin{array}{l}\text { To remedy the swab deficiency with } \\
\text { 3D printing }\end{array}$ & FDM & {$[43]$} \\
\hline Gallup et al & $\begin{array}{l}\text { Phenolic epoxy } \\
\text { resin (head) } \\
\text { PLA/PETG/ABS } \\
\text { (Handle) }\end{array}$ & $\begin{array}{l}\text { Producing easily manufactured and } \\
\text { cost-effective } \\
\text { swabs that will eliminate swab defi- } \\
\text { ciency }\end{array}$ & $\begin{array}{l}\text { SLA and } \\
\text { FDM }\end{array}$ & {$[67]$} \\
\hline $\begin{array}{l}\text { Wolverhampton } \\
\text { University }\end{array}$ & N/A & $\begin{array}{l}\text { To reduce the stress created in the nose } \\
\text { while taking a swab }\end{array}$ & N/A & {$[68]$} \\
\hline
\end{tabular}


can be done to eliminate swab shortages and produced swabs that show similar characteristics to test swabs [43].

Swabs designed and produced by 3D printing can be used in emergency and swab-scarce areas. On the other hand, many of these designs have not received FDA approval. Besides, there are some limitations to the use of design swabs. In particular, issues such as RT-PCR compatibility of swabs for SARS-CoV-2, their effects on the patient and the biocompatibility of the materials used need to be examined. Further, designs made by intellectual property rights should be prevented from being produced for commercial purposes. Despite these limitations, given the need for swabs, we believe that these swabs produced by 3D printing in hospitals and laboratories can be used to diagnose diseased people.

\subsection{Ventilator devices}

1 Ventilators are imperative devices for severe patients suffering from COVID-19 [73, 74]. COVID-19 leads to fibrosis in the lungs of patients and this situation causes patients to have difficulty breathing [73]. In patients who have difficulty breathing, the sufficient amount of oxygen cannot be conveyed in the blood and carbon dioxide cannot be removed as required [74]. Ventilator devices are required to regulate the breathing processes of patients [74]. As a result of the sudden increase in the number of patients at hospitals and in intensive care units, the demand for ventilators worldwide has increased at a time, and almost all hospitals have inadequate number of ventilators [73-75]. To overcome this situation and provide the required amount of ventilator devices to patients and hospitals, the researchers and the engineers have been trying various methods to produce ventilator devices. One of the solutions proposed in this regard is to produce new ventilators by $3 \mathrm{D}$ printing (Table 4 ).

\subsubsection{Ventilators}

Faryami et al. designed and manufactured a ventilation device that used a $3 \mathrm{D}$ vascularized and easily accessible component to eliminate the ventilator deficit (Fig. 7) [76]. This device is an open-source and a positive pressure ventilation device. Some parts of this device are quickly manufactured by $3 \mathrm{D}$ printing. There has been a decrease in the amount of the need for the number of ventilator devices, and a more effective care has been provided to patients [76].

Another study was done by Leitat engineer Magi Galindo who designed an apparatus for breathing devices, and this design was printed with $3 \mathrm{D}$ printers [72]. The device produced was originally described as a ventilator unit. It was later stated to be an emergency unit ventilator. In addition, this 3D-printed ventilator device is approved by the Agencia Española del
Medicamento (Spanish Department of Medicines and Medical Devices).

In another study, a team of engineers and doctors at the University of California developed a quickly-manufacturable, simple and ready-to-use ventilator [77]. The manual design normally featured a mask worn on the patient's face and a hand-wrung bag that allowed air to be delivered to the patient's lungs. Instead of this manual ventilator, they aimed to use 3D-printed parts that could be attached to the engine to compress the bag of the manual ventilator. In this way, the speed and volume of compressions can be controlled, and this automatic system ventilator will provide a more effective application than the manual device.

Another solution offered by researchers to address the need for a ventilator is the conversion of BiPAP used to regenerate the breathing in conditions such as sleep apnoea and congestive heart failure to a positive pressure ventilator. For this purpose, Northwell Health has developed a T-part adapter printed with 3D printers that allows the Philips Respironics V60 BiPAP machine to be turned into a pressure-controlled ventilator, and they can print 150 adapters within $24 \mathrm{~h}$ according to their needs $[78,79]$. As a result of the converted BiPAPs, the need for a ventilator will be reduced.

Another design that can replace a ventilator is a 3D-printed connector designed by Materialise Corporation to distribute oxygen and create high positive pressure without using a ventilator [80]. This non-invasive connector converts standard equipment in use at hospitals into a positive end expiratory pressure (PEEP) mask (nip) that can connect to an oxygen source. This system enables the mechanical ventilators to be used for patients with more critical conditions.

\subsubsection{Splitter}

It was also thought that another way to overcome ventilator distress could be to design and produce separator inserts that allow the use of a single ventilator for more than one patient (Fig. 8). For this purpose, Ayylldı et al. have designed 3Dprinted dividers that allow a single ventilator to be used for multiple patients [73]. In this study, 2-port or 4-port splitters were printed. Nevertheless, it has been noted that it is unlikely to reach the same percentage in ventilation, since the healing process of patients with multiple use will be different.

In another study, Clarke produced a splitter that can be used instead of a T-tube by 3D printing method [81]. Desktop tests have shown that they can be used in short-term emergency ventilation, though in both studies, it was noted that these separator parts designed and experimented with had some restrictions.

Unlike this study, Prisma Health produced a device called a VESper with 3D printing, which allows ventilation to be applied to two patients from a single ventilator [82]. This device has been granted an emergency use permit by the FDA and 
Table 4 Ventilator devices and parts produced by $3 \mathrm{D}$ printing

\begin{tabular}{|c|c|c|c|c|}
\hline \multicolumn{5}{|l|}{ Ventilator devices } \\
\hline Producer & Materials & Purposes & Method & References \\
\hline \multicolumn{5}{|l|}{ Ventilators } \\
\hline Faryami et al. & PLA & $\begin{array}{l}\text { To create a device that can be produced } \\
\text { quickly and } \\
\text { easily to meet the need for ventilation } \\
\text { devices }\end{array}$ & FDM & [73] \\
\hline Leitat & N/A & To produce an emergency ventilator & FDM & {$[68]$} \\
\hline California University & N/A & $\begin{array}{l}\text { To produce a ventilator device that } \\
\text { provides an eating } \\
\text { setup for patients who need a } \\
\text { ventilator }\end{array}$ & FDM & {$[74]$} \\
\hline Northwell Health & N/A & $\begin{array}{l}\text { To convert the V60 BiPAP machine to a } \\
\text { ventilator }\end{array}$ & FDM & {$[75,76]$} \\
\hline Materialise & N/A & $\begin{array}{l}\text { To provide patients with high positive } \\
\text { pressure outside of ventilator devices }\end{array}$ & FDM & [77] \\
\hline \multicolumn{5}{|l|}{ Splitter } \\
\hline Ayyildiz et al. & Acrylic resin & $\begin{array}{l}\text { To create an intensive care ventilator to } \\
\text { serve } \\
\text { multiple patients in the emergency } \\
\text { departments }\end{array}$ & PolyJet & {$[70]$} \\
\hline Clarke & N/A & $\begin{array}{l}\text { To create an intensive care ventilator to } \\
\text { serve } \\
\text { multiple patients in the emergency } \\
\text { departments }\end{array}$ & FDM & {$[78]$} \\
\hline $\begin{array}{l}\text { Prisma Health, Johnson } \\
\quad \text { \& Johnson }\end{array}$ & N/A & $\begin{array}{l}\text { To create an intensive care ventilator to } \\
\text { serve } \\
\text { multiple patients in the emergency } \\
\text { departments }\end{array}$ & FDM & {$[79]$} \\
\hline \multicolumn{5}{|c|}{ cop } \\
\hline Fraccasi et al. & N/A & $\begin{array}{l}\text { To produce the required valves by the } \\
3 \mathrm{D} \text { printing method }\end{array}$ & FDM & {$[80]$} \\
\hline Photocentric & $\begin{array}{c}\text { Photoresin } \\
\text { (RG35) }\end{array}$ & $\begin{array}{l}\text { To produce large quantities of valves } \\
\text { quickly }\end{array}$ & SLA & {$[81]$} \\
\hline CRP Technology & Wildform P1 & $\begin{array}{l}\text { To produce Charlotte valves that are fast, } \\
\text { cheap and in abundant to create } \\
\text { ventilators }\end{array}$ & HSS & {$[82,83]$} \\
\hline Ferrari/Mares & Nylon 12 & $\begin{array}{l}\text { To produce large quantities of valves } \\
\text { quickly }\end{array}$ & FDM & [84] \\
\hline
\end{tabular}

Fig. 7 3D-printed ventilators. a System designed by Faryami et al. [76] and b LEITAT 1 ventilator system [72])
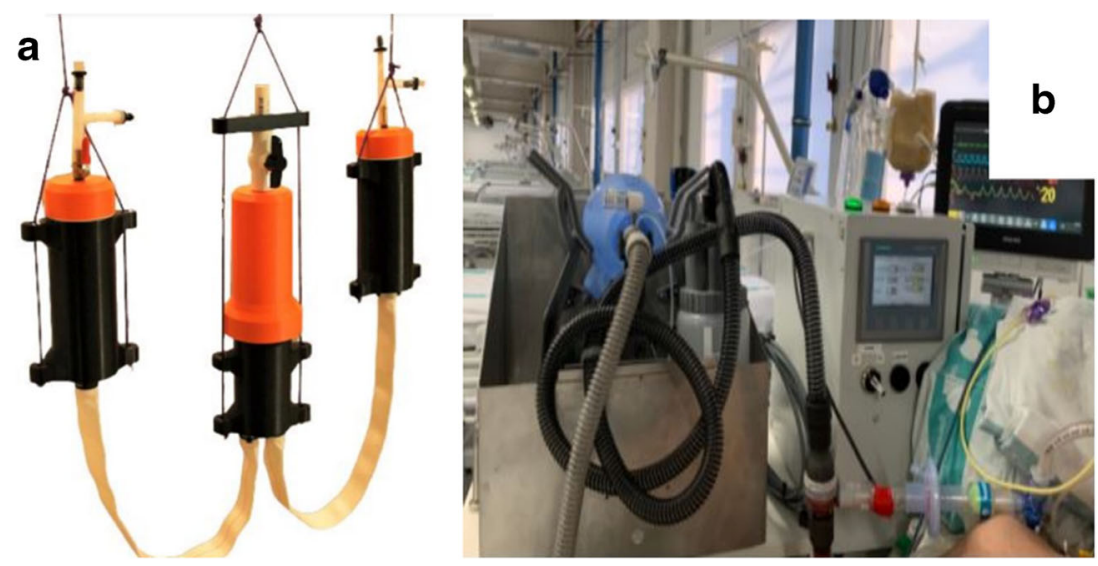


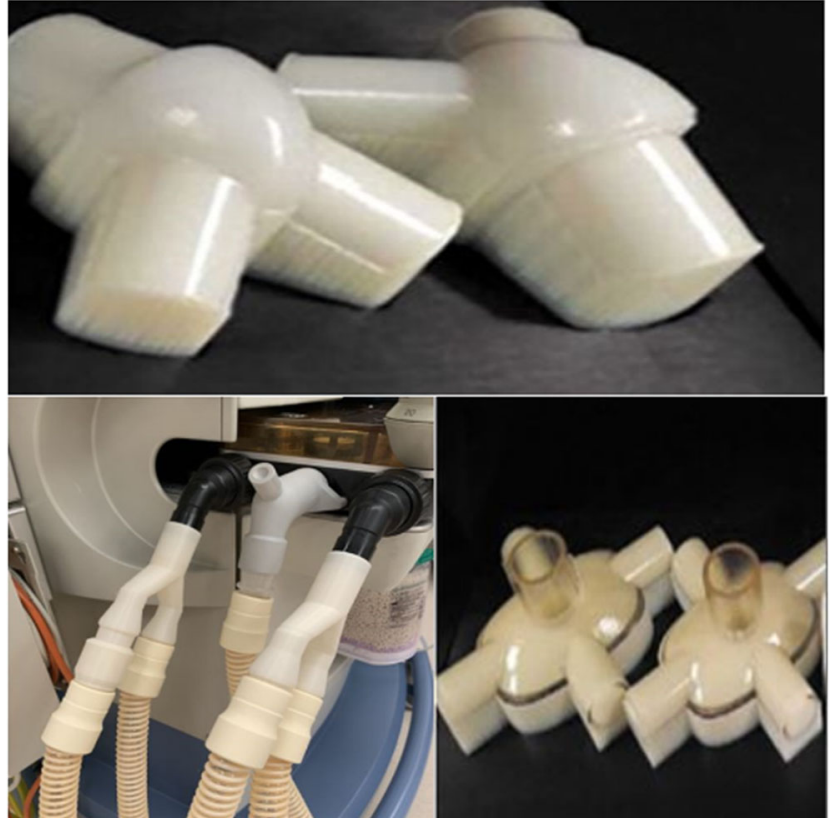

Fig. 8 Splitters manufactured in a 3D printer $[73,81]$

allows more patients to be given ventilation during the pandemic.

\subsubsection{Valves}

Valves are parts that are connected to the patient's mask in order to ensure that oxygen is delivered from ventilators to patients at constant concentration (Fig. 9). These parts have to be patient-specific and replaced in devices after each use. As a result of the increase in the number of patients and the constant arrival of new patients, there are not enough valves in hospitals. In order to overcome this problem, research and studies have been carried out on the production of valves by $3 \mathrm{D}$ printing method [75]. In a study conducted for this purpose, Fracassi et al. eliminated the need for valves used in breathing apparatus of a hospital in Italy by producing 3D-printed valves [83]. They managed to meet the needs of the hospital in Brescia by printing 100 valves ready for use in $24 \mathrm{~h}$ on $3 \mathrm{D}$ printers. Different companies also made productions on this subject. For example, the company Photocentric also reported that they can produce more than 40,000 3D-printed valves for use in ventilators at 1 week [84]. CRP Technology also produced functional prototypes of emergency valves $[85,86]$. In addition to these valves, they also manufactured valves called "Charlotte valves", that are the emergency ventilator mask connection component, by 3D printing method. Other 3Dprinted valves designed to fit scuba masks are manufactured by Ferrari [87]. This production was made in conjunction with Mares, a manufacturer of diving equipment.
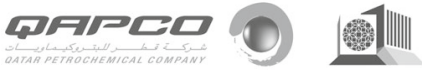

جامعة قطر QATAR UNIVERSITY

\subsection{Other auxiliary equipment}

In addition to masks, face spears, swabs, ventilators and valves, many different equipment have been made by $3 \mathrm{D}$ printing in order to make people's life easier and eliminate deficiencies in the fight against COVID-19 (Table 5). These various equipment produced are described in Table 5.

\subsubsection{D printing lung model}

Teams from Axial3D and the Belfast Health and Social Care Foundation printed a 3D lung model of a patient in the fourteenth day of catching up with the infection by using CT scanners $[88,92]$. The effect of the virus on the lungs of the patient was visualized in this model. Moreover, the lung damage caused by the SARS-CoV-2 was better understood with this lung model (Fig. 10).

\subsubsection{Endotracheal tube clamp}

Aerosol emission due to the endotracheal tube (ETT) is the most severe way of exposure to the virus for health workers. In order to reduce this aerosol particle distribution, the ETT attached to the ventilator has to be compressed. Jacop et al. have proposed a 3D-printed disposable clamp design that allows the performance of several procedures such as tightening and opening during intubation/extubation (Fig. 11) [89]. The main purpose of this equipment is to compress ETT and prevent aerosol emission, protecting the health of health workers from the viruses.

\subsubsection{Button pusher}

Due to the high probability of the virus spreading from various common devices such as elevator buttons, ATM buttons, keyboard, mouse and phone, studies have been made to find a solution to this issue. Button pushers made by François et al. aim to minimize this risk [90]. It has a cylindrical shape and contains a tip. This tip can be taken out of the cylinder and retracted after use. This apparatus is also printed using a 3D printer (Fig. 12).

\subsubsection{Door opener}

The usage of door handles in public places or workplaces can increase the spread of SARS-CoV-2. For this reason, an auxiliary apparatus was designed to open the door. François et al. designed hand-free door openers suitable for the door handle for this purpose, and they have obtained these apparatuses with a $3 \mathrm{D}$ printing device. Hand-free door openers are attached to the door handles. Apparatuses are fixed to the door handle using clips on a straight handle or cable. The door is opened using an elbow or forearm. At the same time, the 
Fig. 9 3D-printed valves with different designs

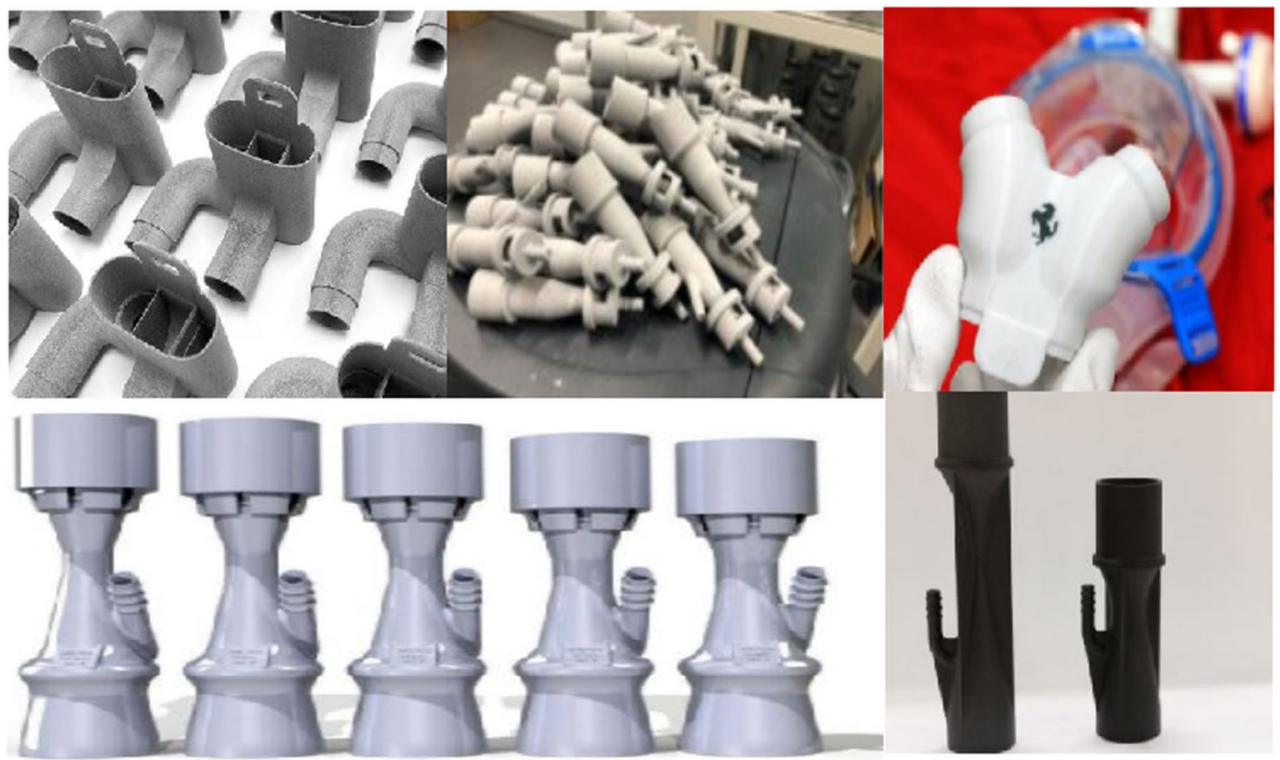

apparatus is quick to manufacture and easy to clean and fit. Thus, it is used in many hospitals in Paris. Materialise company has also developed narrow and wide hand-free door openers for home type and door types with above average weight for the same purpose [91]. Likewise, these openers come in different designs for cylindrical-, rectangular-, circular-, bar- and circular-type door handles. Thus, they aimed to minimize the spread of the virus from door handles. The door should be opened with the help of door openers using handles and elbows, and the door openers should be disinfected regularly.

In addition to door openers, they also worked on door hooks using a 3D printer. While some door handles are not proper for a door opener design, a door hook has been developed using an easily retractable sheath [90] (Fig. 13).
Table 5 Other auxiliary equipment produced by $3 \mathrm{D}$ printing

\begin{tabular}{|c|c|c|c|c|}
\hline \multicolumn{5}{|c|}{ Other Auxiliary equipment } \\
\hline Producer & Materials & Purposes & Method & References \\
\hline \multicolumn{5}{|l|}{ Lung model } \\
\hline $\begin{array}{l}\text { Axial3D/Belfast } \\
\text { Health and } \\
\quad \text { Social }\end{array}$ & Resin & $\begin{array}{l}\text { To observe the effect of COVID-19 disease on } \\
\text { the lungs }\end{array}$ & SLA & {$[85,86]$} \\
\hline \multicolumn{5}{|c|}{$\begin{array}{l}\text { Care } \\
\quad \text { Foundation } \\
\text { Endotracheal tube clamp }\end{array}$} \\
\hline Jacob et al. & PLA & $\begin{array}{l}\text { To reduce the possibility of endotracheal tube } \\
\text { virus transmission }\end{array}$ & N/A & [87] \\
\hline \multicolumn{5}{|l|}{ Button pusher } \\
\hline $\begin{array}{l}\text { François et al. } \\
\text { Isolation ward }\end{array}$ & ABS & To reduce contact with door handles & FDM & {$[88]$} \\
\hline Winsun & $\begin{array}{l}\text { Urban } \\
\text { Construction } \\
\text { Waste }\end{array}$ & $\begin{array}{l}\text { To meet the need for a clean room from } \\
\text { COVID-19 in hospitals }\end{array}$ & $\mathrm{N} / \mathrm{A}$ & [89] \\
\hline \multicolumn{5}{|l|}{ Water circulator } \\
\hline $\begin{array}{l}\text { Gonzales et al. } \\
\text { Bottle holder }\end{array}$ & N/A & To create an incubation room for PCR tubes & N/A & {$[90]$} \\
\hline Moath Abuysha & N/A & $\begin{array}{l}\text { To provide an easy handling of disinfectant } \\
\text { bottles }\end{array}$ & $\mathrm{N} / \mathrm{A}$ & [91] \\
\hline
\end{tabular}


Fig. 10 3D-printed lung model belonging to COVID-19 patients [88]

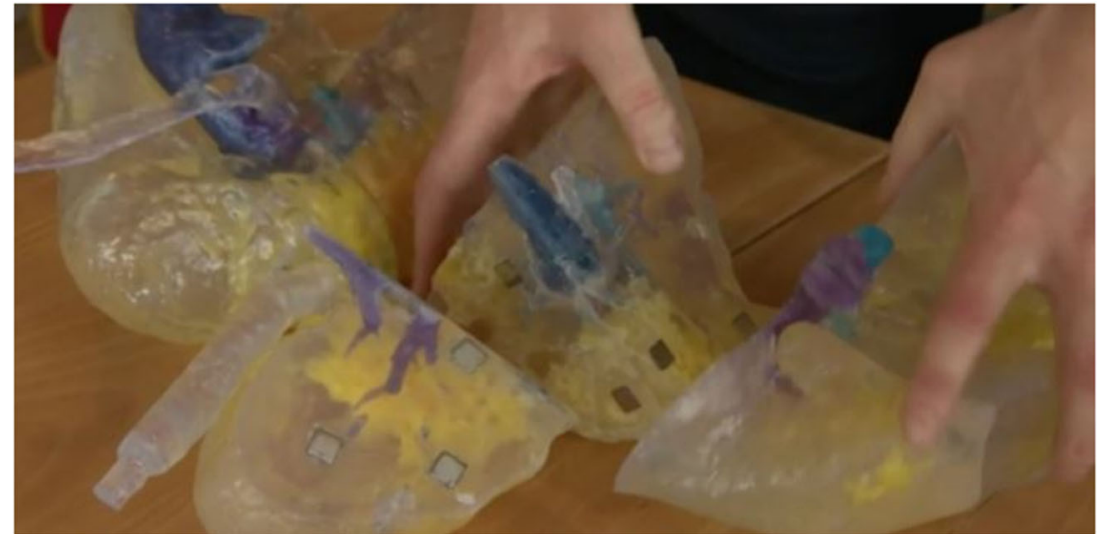

\subsubsection{Isolation ward}

Due to the COVID-19 outbreak, the need for beds and clean rooms in hospitals has increased. China-based 3D printing company Winsun builds 3D-printed rooms using solid urban construction waste to address the lack of beds and clean rooms in hospitals (Fig. 14) [93]. For this purpose, fifteen 3D-printed quarantine rooms were first sent to Xianning Central Hospital.

\subsubsection{Water circulator}

Unlike other designs, Gonzalez and colleagues used a 3Dprinted design for use in an experimental method [94]. The method proposes the combined use of a 3D-printed incubator for commercial Eppendorf PCR tubes and a colorimetric arrangement of a loop-mediated isothermal amplification (LAMP) reaction scheme for the detection of SARS-CoV-2. The combined LAMP system states that RT-qPCR may be a suitable method for COVID-19 testing when it is not possible or unavailable. They also note that the fact that this system is portable, easy to use and reproducible makes it a reliable alternative for deploying SARS-CoV-2 detection efforts during pandemics.

\subsubsection{Bottle holder}

Another design that seems plain but is crucial is a 3D-printed wrist buckle made by Moath Abuysha to hold a disinfectant bottle. Disinfection of hands with this wrist buckle is achieved without polluting the bottle with antiseptic gel inside the bottle [95] (Fig. 15).

\subsubsection{D-printed drone}

In China, drones or unmanned aerial vehicles (UAVs), some parts of which are manufactured in a 3D printer, are used for disease control purposes [95].

\subsection{Drug delivery}

Drug delivery system is a technology that enables the therapeutic agent to be delivered directly to the target cell, tissue or organ. Studies with 3D printers can provide a system in which personal doses can be prepared to meet the drug needs of patients. How to obtain tablets that can release the desired dose or release systems using 3D printers is among the current research topics. In 2015, the first 3D printing drug was approved by the US Food and Drug Administration. Thus, stud-
Fig. 11 Endotracheal tube clamp [89]

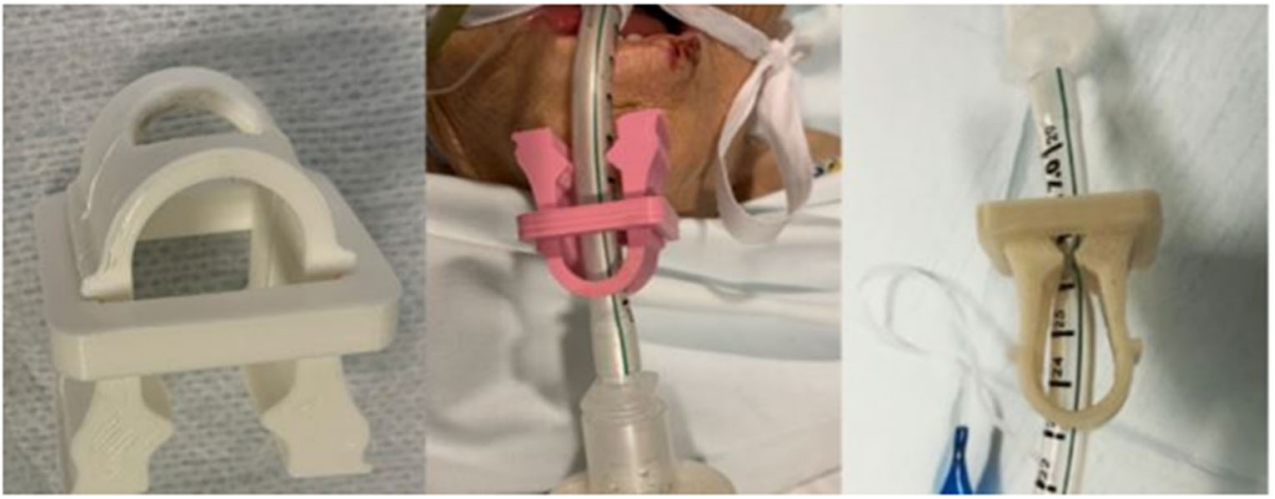


Fig. 12 Button pusher: a close and $\mathbf{b}$ open [90]
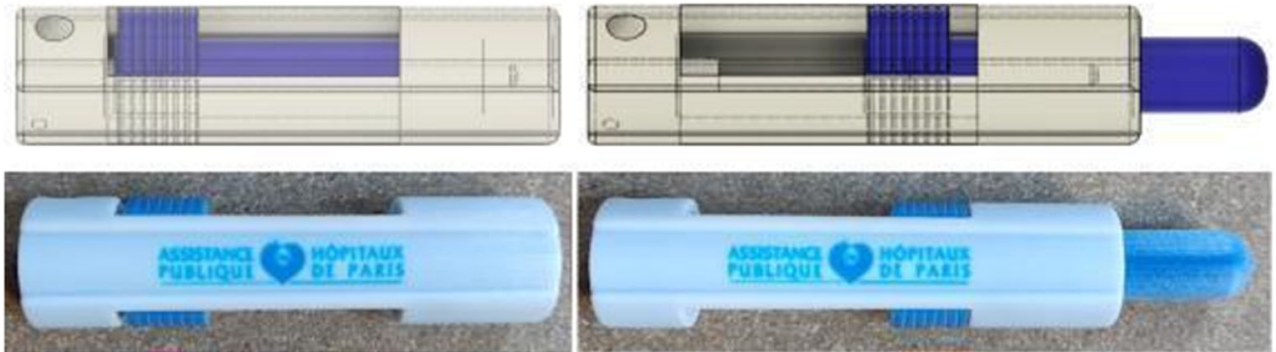

a

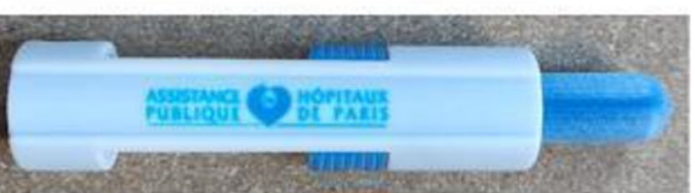

b ies on 3D printing drugs have increased. Studies are conducted on drugs with immediate or continuous release properties. $3 \mathrm{D}$ printing systems contain a large number of drug components and have a polymer matrix. Besides this technology, it is thought that the mandatory drug delivery can be provided for the recovery of COVID-19 patients. In addition, systems that can deliver different amounts of drugs by calculating according to the genetic and physical characteristics of the person can also be used in the treatment of COVID-19 patients. Although there are not many studies in this area, drug transport systems that can be done with a $3 \mathrm{D}$ printer can be designed in COVID-19 patients $[61,96]$.

\section{How can damaged organs be treated in COVID-19 patients with 3D printing?}

In this section, studies on the treatment of damage caused by SARS-CoV-2 on different organs and systems using a 3D printing method are mentioned.

\subsection{Respiratory system}

Overexpression of cytokines is a common symptom for COVID-19. The overexpression of cytokines causes oedema, acute respiratory distress syndrome (ARDS) and lung tissue damage. As a result of its regenerative properties and antiinflammatory capacity, MSCs can provide repair of damaged lung tissue caused by COVID-19. Additionally, MSCs have been noted to stabilize endothelial fluid leakage and reduce alveolar-capillary barrier function, thereby reducing the development of interstitial lung oedema [97]. Nichols et al. stated that from natural rat lungs, acellular tracheal lung scaffolds can be produced and protect important components of the extracellular matrix and can be used to produce lung tissue by re-cellularization using embryonic stem cells [98]. The obtained results are encouraging and suggest that repopulation of the lung matrix is an appropriate strategy for lung regeneration [99]. Macchiarini et al. have developed a new method for airway replacement in a human by tissue engineering [100]. Cells and MHC antigens were removed from the donor trachea; then, it is cultured with the mesenchymal stem cells and epithelial cells, which are from the recipient. The graft was then implanted into the patient to replace the left main bronchus of the recipient. Based on the results, the graft provided the recipient with a functional airway quickly, further improving the quality of life and resulting in a normal appearance and mechanical properties in about 4 months. In this way, damage to the respiratory tract after COVID-19 can be corrected with an implantable airway that has the same mechanical properties as the natural airway. In addition, the risk of immune rejection is eliminated with this method. Takabe et al. have studied liver production using human-derived pluripotent stem cells. Vascularized and functional human liver production was performed using liver buds and induced pluripotent stem cells created in vitro. Human transplantation has
Fig. 13 Hand-free door opener [90]
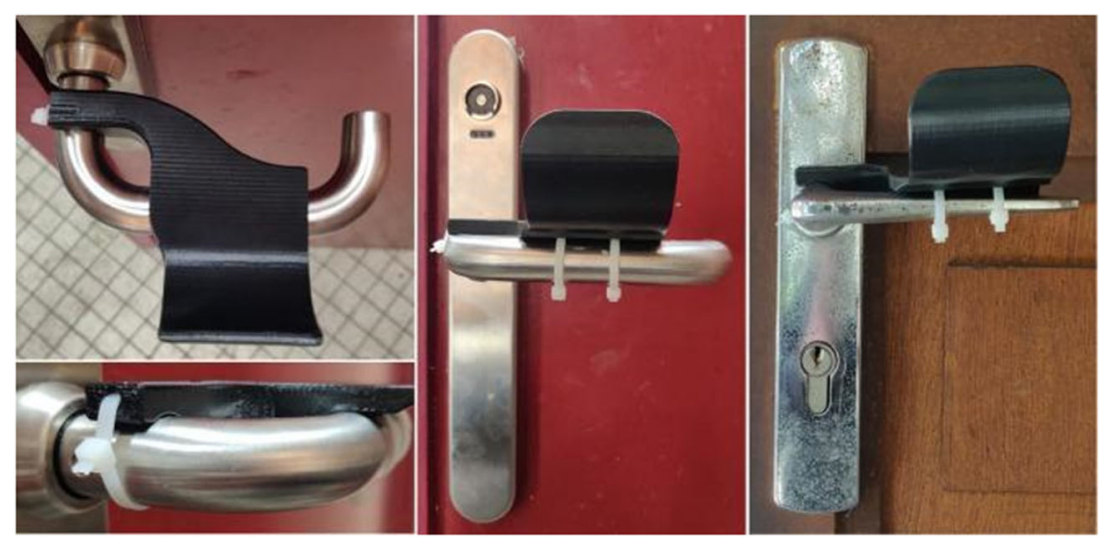


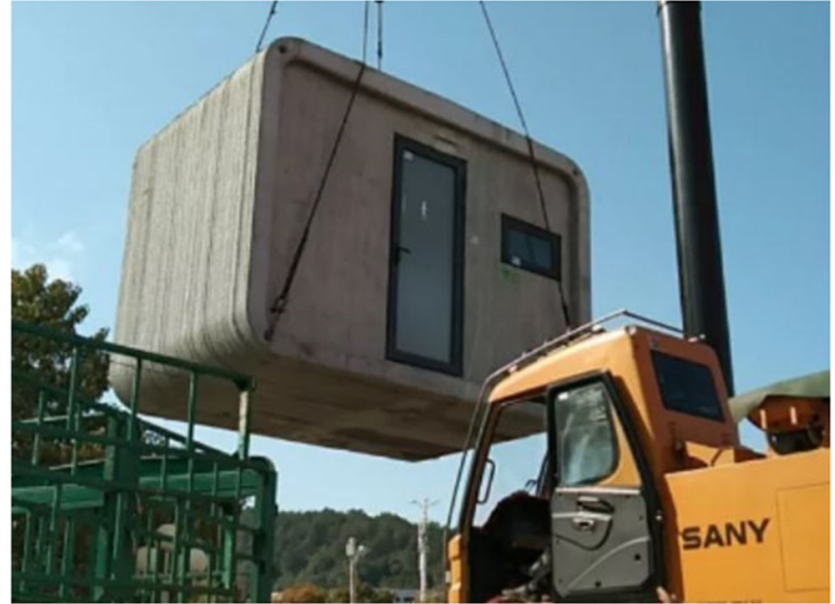

Fig. 14 3D-printed isolation ward [93]

not been performed, but the results have been reported to be promising [101]. This current study could be improved to prevent severe liver damage from COVID-19.

\subsection{Cardiovascular system}

Patients who have cardiovascular disease before the pandemic have worse consequences and increased risk of death with COVID-19. Additionally, COVID-19 is able to enhance myocardial injury, arrhythmias, acute coronary syndrome and thromboembolism. Besides, it has been defined that there can be a possible link between COVID-19 and Kawasaki disease-like syndrome in kids. Lastly, reduced physical activity because of the quarantine might also induce cardiovascular risk factors [102].

3D printing techniques might be useful for the treatment of cardiovascular diseases and complications. For instance, there is a study assessing the treatment of myocardial injury that contains 3D-printed stem cell-loaded micro-channelled hydrogel patch to better achieve the therapeutic potential of the

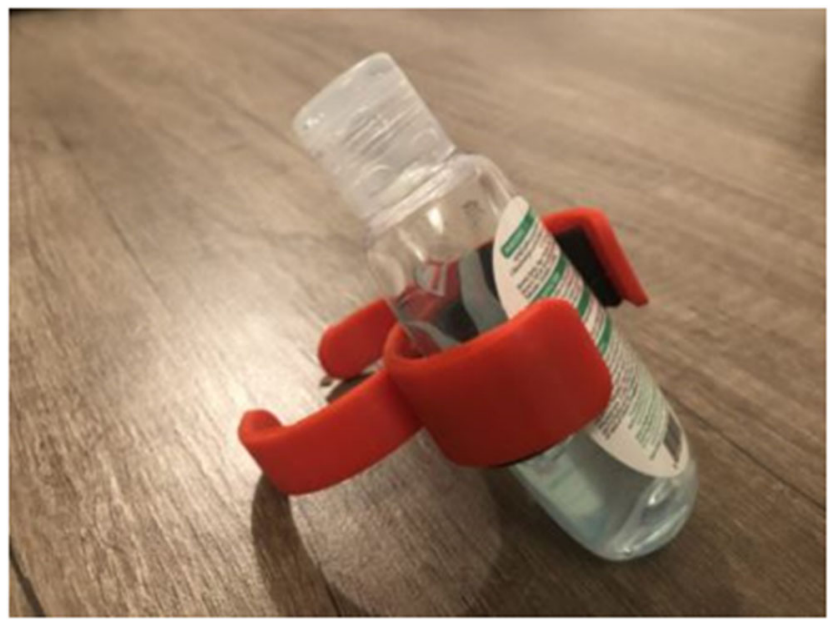

Fig. 15 Hand-free door opener [95] cells and reduce the degradation of myocardial tissue postinfarction. As a result of this study, it can be seen that the microchannels sharply decreased the cells number needed to recover cardiac function (Fig. 16) [103].

\subsection{Nervous system}

The fact that SARS-CoV-2 infects cells with the ACE-2 receptor strengthens the possibility that the virus may affect the nervous system [13]. As a result of the studies, it was observed that SARS-COV-2 causes complications and diseases that damage the nervous system, such as viral encephalitis, infectious toxic encephalopathy and stroke [104]. In addition, some researchers believe that sensitivity to neurological syndromes may be increased by triggering systemic inflammation as a result of SARS-CoV-2 infection. In addition, SARS-CoV-2 is thought to be able to trigger neurodegenerative diseases [105]. Considering its negative effects on the nervous system, SARS-CoV-2 can cause nerve degeneration. For this reason, the importance of studies on nerve cell regeneration has increased even more.

$3 \mathrm{D}$ printing is a promising method for the regeneration of the nervous system. There are many studies on the use of 3D printing for nervous system regeneration. 3D-printed scaffolds are often used as a model to understand the structure of the brain [106]. In a study conducted for this purpose, Lozano et al. produced 3D-printed brain-like structures with multiple cortical layers, encapsulated with gellan gum hydrogel modified with RGD [107]. In the study, it was observed that the neurons encapsulated in the structure showed $80 \%$ viability, and the encapsulated neurons were able to differentiate into glia (Lee et al.). Amine-functionalized multi-walled carbon nanotubes (MWCNTs) combined with PEGDA polymer produced scaffolding using 3D printing [108]. As a result of the study, it has been reported that the multi-walled carbon nanotube (MWCNT) scaffold promotes the growth of neutralite. In another study, gelatin methacrylatedopamine (GelMA-DA) nerve scaffolds with hierarchical structures were manufactured in 3D using our specially designed stereolithography-based printer [109]. This study indicates that 3D-printed customizable GelMA-DA scaffolds have a positive role in promoting neural differentiation, promising for future nerve repair and regeneration. Although 3D-printed scaffolds offer positive results for the treatment of nerve damage, they are not yet sufficient for the final treatment of central nervous system damage. For this reason, more research should be done on 3D-printed scaffolds.

\subsection{Reproductive and excretory system}

Results of tests performed on samples taken from the urine of COVID-19 patients indicated that these patients

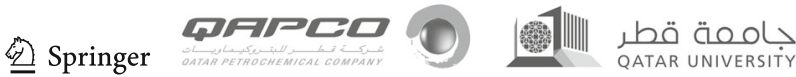




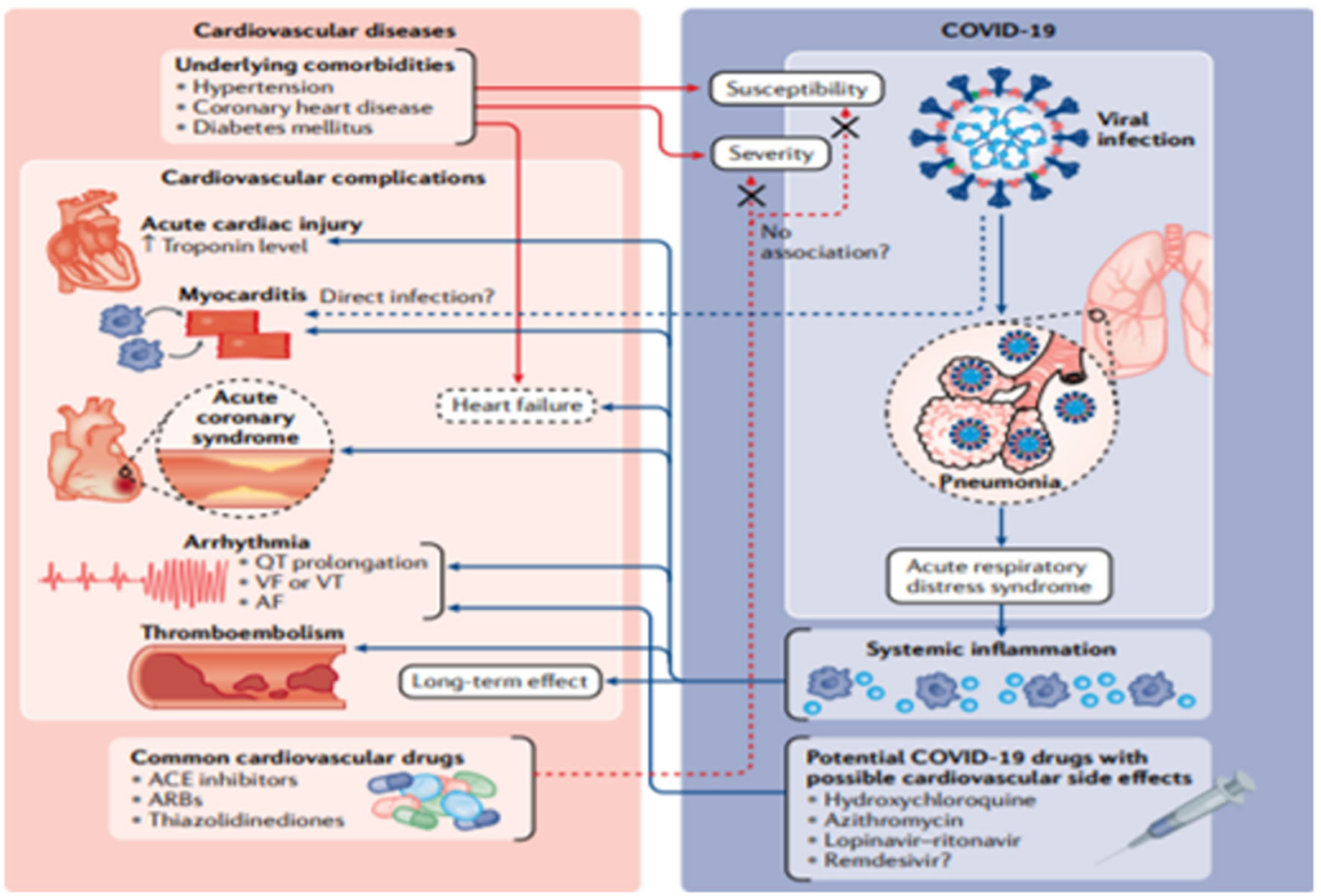

Fig. 16 Interactions among cardiovascular diseases and COVID-19 [103]

had high concentrations of protein, blood urea nitrogen and plasma creatinine [110]. Concurrently, this virus has been isolated from the urine of COVID-19-infected patients with recent studies. Thus, it was concluded that the virus harms the kidneys [111]. Although the exact mechanism by which the virus damages the kidneys is not known, there are many possible mechanisms. Dialysis is the most commonly used treatment for nonfunctioning kidneys. However, today, there are a lot of researches on 3D-printed kidneys [112]. Therefore, damages can be solved by $3 \mathrm{D}$ printing. For example, in a study by Kusaka et al., kidneys were obtained with a 3D printer designed with personal simulation for kidney transplantation [113]. It was concluded that using the personalized kidney graft and the pelvic cavity copy for simulating kidney transplant surgeries may be beneficial for doctors and their assistants. For this study, a 3D model was obtained by transferring the results obtained from medical imaging techniques to software programs. TangoPlus, VeroWhitePlus and VeroMagenta materials were used to obtain 3D models. It is concluded that these copies can be successful for preoperative simulation and navigation. Due to the complex structure of the kidney, kidney production with $3 \mathrm{D}$ technology is very difficult, but obtaining the kidney structure with this simulation has created a resource for artificial kidneys. However, studies are conducted on the production of mini-tissue structures for the kidney. King et al. succeeded in constructing kidney tubules with 3D printing technique [114].

By the isolation of the virus from the urine, the possibility has arisen that this virus could directly damage the bladder by binding to the receptors [115]. Although there is no definite information in this direction yet, this situation may cause acute or chronic diseases in the urinary system. Organ acquisition by 3D printing method started in 1999 and the first 3D printing bladder was implanted into the human body [116]. In 2004, as a result of studies carried out by Dr. Atala, a 3D bio-printed bladder was implanted in a child with a damaged bladder [117]. Dr. Atala acquired a scaffold with an inkjet printer and used the patient's cells to grow a bladder within 2 months. The implantation process has been successful.

Receptors to which SARS-CoV-2 binds are also expressed in the female and male reproductive systems $[118,119]$. Thus, these systems become potential infection sites for the virus. Although it is not known exactly, it is thought that this virus may cause some acute or chronic functional losses on the reproductive system. In the reproductive system, there are studies of obtaining the desired tissue by printing the scaffold with polymers such as PLA using a $3 \mathrm{D}$ printer and then seeding it with its own cells $[120,121]$. 


\section{Benefits and challenges of 3D printing}

There are numerous benefits and challenges of 3D printing. The presented ones in this part are the least, but not last. The list was kept short due to space limitation.

\subsection{Benefits}

There are undeniable benefits of 3D printing such as freedom of design, mass customization, waste minimization, the ability to manufacture complex structures and fast prototyping [23]. The selected and exemplified benefits of $3 \mathrm{D}$ printing are listed below:

- In terms of methods, fused deposition modelling (FDM) is one of the most common 3D printing technologies because of its low-cost, simplicity and high-speed processing.

- The benefits of metal additive manufacturing are reduced tooling costs, freedom of design and manufacturing of complex and lightweight structures and presence of multiple part consolidation, which can eliminate part assemblies [23].

- 3D printing of porous ceramics or lattices introduced numerous benefits by developing advanced lightweight materials that are tailored for different applications. Ceramic scaffolds used in tissue engineering have become more convenient and faster compared to traditional methods of casting and sintering [122].

- A significant benefit of bio-printing is that it prevents homogeneity issues that accompany post-fabrication cell seeding, as cell placement is included during fabrication. The advantages of homogeneously distributed cell-laden scaffolds have been demonstrated by faster integration with the host tissue, lower risk of rejection and uniform tissue growth in vivo [123].

\subsection{Challenges}

There are several challenges in the field of 3D printing that would require further research and technological development. These challenges include high costs, limited applications in large structures and mass production, inferior and anisotropic mechanical properties and limitation of materials and defects [23]. The selected and exemplified challenges are listed as follows:

- At present, there are no valid regulations concerning design, manufacturing process and quality testing considerations. To overcome this issue, there is a strong need to make some regulations for those particular groups of manufacturing methods [124].
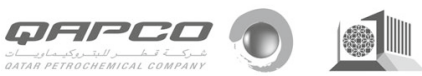

- The limited materials available for 3D printing pose challenges in utilizing 3D technology in different industries. To handle this limitation, there is a need for developing suitable materials that can be used for 3D printing. Further, developments are also needed to enhance the mechanical properties of 3D-printed parts [23].

- Additive manufacturing has become an essential method for manufacturing of advanced ceramics for biomaterials and tissue engineering, e.g. scaffolds for bones and teeth. Despite the accuracy of printing, layer-by-layer appearance and a limited selection of materials are the main challenges for 3D printing of ceramics [125].

- The long processing time and higher cost of 3D printing are the main challenges that inhibit the mass production of any repetitive parts, which can easily be performed by other conventional methods at a fraction of the time and cost [23].

\section{Conclusion and future perspective}

In this study, 3D printing technology and its applications were reviewed to counter COVID-19 pandemic and diminish pandemic-related emerging causes. The main methods applied and the materials used in 3D technology were identified in addition to trending applications in this emerging sector. It has been obvious that there is an immense role of $3 \mathrm{D}$ printing for combatting against COVID-19 through layered manufacturing of face masks and face shields; auxiliary accessories, door opener and button pusher have been discovered as possibilities and opportunities. The main challenges and undeniable benefits of 3D printing were identified and listed in detail. Several future perspectives or trends for further research in $3 \mathrm{D}$ printing were summarized below:

- Future trends in 3D printing may concentrate on the gaps for further development and improvement. The development of automatic methods to combine CT scan results and design analyses with AM technologies can manufacture patient-specific implants quickly [23].

- Research and development may help to upscale bioprinted scaffolds and tissues for clinical applications and to improve the cost-effectiveness of AM for tissue engineering. Therefore, in situ repair of organs and tissues would become possible in the future [126].

- Inkjet bio-printing is of great interest as it exhibits high resolution and cell viability. With this process, an accurate position of multiple cell types is possible [127]. However, the limitations of vertical printing and restricted viscosities may mean that inkjet bio-printing needs to be combined with other printing techniques for future developments. 


\section{References}

1. M. Cascella, M. Rajnik, A. Cuomo, S.C. Dulebohn, R. Di Napoli, Features, evaluation, and treatment of coronavirus (COVID-19) (2020) (StatPearls Publishing, Treasure Island, 2020)

2. World Health Organization, Information of COVID-19 datas, COVID-19 formal website, Accessed 16.09.2020

3. G. Li, Y. Fan, Y. Lai, T. Han, Z. Li, P. Zhou, P. Pan, W. Wang, D. $\mathrm{Hu}, \mathrm{X}$. Liu, Q. Zhang, J. Wu, Coronavirus infections and immune responses. J. Med. Virol. 92, 424-432 (2020). https://doi.org/10. 1002/jmv. 2568

4. F. He, Y. Deng, W. Li, Coronavirus disease 2019: what we know? J. Med. Virol. 92, 719-725 (2020). https://doi.org/10.1002/jmv. 25766

5. World Health Organization, Q\&A on coronaviruses (Covid-19), what are the symptoms of COVID-19? https://www.who.int/ emergencies/diseases/novel-coronavirus-2019/question-andanswers-hub/q-a-detail/q-a-coronaviruses. Accessed 20 August 2020

6. T. Singhal, A review of coronavirus disease-2019 (COVID-19). Ind. J. Pediatri 87, 281-286 (2020). https://doi.org/10.1007/ s12098-020-03263-6

7. E. Livingston, A. Desai, M. Berkwits, Purcing Personal Protective Equipment During the COVID-19 Pandemic. JAMA 323, 19121914 (2020). https://doi.org/10.1001/jama.2020.5317

8. M.F. Coakley, D.E. Hurt, N. Weber, M. Mtingwa, E.C. Fincher, V. Alekseyev, D.T. Chen, A. Yun, M. Gizaw, J. Swan, T.S. Yoo, Y. Huyen, The NIH 3D print exchange: a public resource for bioscientific and biomedical 3D prints. 3D Print. Addit. Manuf. 1, 137-140 (2014). https://doi.org/10.1089/3dp.2014.1503

9. C. Schubert, M.C. Langeveld, L.A. Donoso, Innovations in 3D printing: a 3D overview from optics to organs. Br. J. Ophthalmol. 98, 159-161 (2013). https://doi.org/10.1136/bjophthalmol-2013304446

10. J.-Y. Lee, W.S. Tan, J. An, C.K. Chua, C.Y. Tang, A.G. Fane, T.H. Chong, The potential to enhance membrane module design with 3D printing technology. J. Membr. Sci. 499, 480-490 (2015). https://doi.org/10.1016/j.memsci.2015.11.008

11. J.-Y. Lee, J. An, C.K. Chua, Fundamentals and applications of 3D printing for novel materials. Appl. Mater. Today 7, 120-133 (2017). https://doi.org/10.1016/j.apmt.2017.02.004

12. F. Song, N. Shi, F. Shan, Z. Zhang, J. Shen, H. Lu, Y. Li, Y. Jiang, Y. Shi, Emerging coronavirus 2019-nCoV pneumonia. Radiology 295, 210-217 (2020). https://doi.org/10.1148/radiol.2020200274

13. M.-Y. Li, L. Li, Y. Zhang, X.-S. Wang, Expression of the SARSCoV-2 cell receptor gene ACE2 in a wide variety of human tissues. Infect. Dis. Poverty 9, 45 (2020). https://doi.org/10.1186/ s40249-020-00662-x

14. M.R. Mehra, S.S. Desai, S. Kuy, T.D. Henry, A.N. Patel, Cardiovascular disease, drug therapy, and mortality in Covid-19. N. Engl. J. Med. 382, e102 (2020). https://doi.org/10.1056/ NEJMoa2007621

15. A. Bernheim, X. Mei, M. Huang, Y. Yang, Z.A. Fayad, N. Zhang, K. Diao, B. Lin, X. Zhu, K. Li, S. Li, H. Shan, A. Jacobi, M. Chung, Chest CT findings in coronavirus disease 2019 (COVID19): relationship to duration of infection. Radiology 295, 685-691 (2020). https://doi.org/10.1148/radiol.2020200463

16. R. Hamutoğlu, S. Ünver Saraydın, Effects of COVID-19 on digestive system. Ankara Eğitim ve Araștırma Hastanesi Tıp Dergisi 53, 76-81 (2020)

17. K.J. Clerkin, J.A. Fried, J. Raikhelkar, G. Sayer, J.M. Griffin, A. Masoumi, S.S. Jain, D. Burkhoff, D. Kumaraiah, L. Rabbani, A. Schwartz, N. Uriel, COVID-19 and cardiovascular disease. Circulation 141, 1648-1655 (2020). https://doi.org/10.1161/ CIRCULATIONAHA.120.046941
18. Z. Cormier, How Covid-19 can damage the brain. BBC Future (2020). https://www.bbc.com/future/article/20200622-the-longterm-effects-of-covid-19-infection\#: :text=Now $\% 2 \mathrm{C} \% 20 \mathrm{more} \%$ 20 than $\% 20300 \% 20$ studies,speak) $\% 2 \mathrm{C} \% 20$ strokes $\% 20$ and $\%$ 20seizures. Accessed 15 September 2020

19. K. Gander, COVID-19 Linked to some types of brain damage: study. Newsweek (2020) Retrieved from: https://www.newsweek. $\mathrm{com} /$ brain-damage-coronavirus-1516283

20. C.J. Sperati, Coronavirus: kidney damage caused by COVID-19 (John Hopkins Medicine, 2020) https://www.hopkinsmedicine. $\mathrm{org} /$ health/conditions-and-diseases/coronavirus/coronaviruskidney-damage-caused-by-covid19. Accessed 16 September 2020

21. L. Ioannou, High odds severe Covid-19 can lead to kidney injury or failure, medical studies reveal. News Break (2020) https:// www.newsbreak.com/news/1610780881603/high-odds-severecovid-19-can-lead-to-kidney-injury-or-failure-medical-studiesreveal. Accessed 16 September 2020

22. Q. Yan, H. Dong, J. Su, J. Han, B. Song, Q. Wei, Y. Shi, A review of 3D printing technology for medical applications. Engineering 4, 729-742 (2018). https://doi.org/10.1016/j.eng.2018.07.021

23. T.D. Ngo, A. Kashani, G. Imbalzano, K.T.Q. Nguyen, D. Hui, Additive manufacturing (3D printing): a review of materials, methods, applications and challenges. Compos. Part B 143, 172-196 (2018). https://doi.org/10.1016/j.compositesb.2018.02. 012

24. N.J. Mardis, Emerging Technology and Applications of 3D Printing in the Medical Field. Mo. Med. 115, 368-373 (2018)

25. S. Sharma, S. Goel, 3D Printing and its future in medical world. J. Med. Res. Innov. 3, e000141 (2019). https://doi.org/10.15419/ jmri.141

26. N. Shahrubudin, T.C. Lee, R. Ramlan, An overview on 3D printing technology: technological, materials, and applications. Procedia Manufactur. 35, 1286-1296 (2019). https://doi.org/10. 1016/j.promfg.2019.06.089

27. C.L. Ventola, Medical applications for 3D printing: current and projected uses. P \& T 39, 704-711 (2014)

28. D. Ahn, L.M. Stevens, K. Zhou, Z.A. Page, Rapid high-resolution visible light 3D printing. ACS Central Sci. (2020). https://doi.org/ 10.1021/acscentsci.0c00929

29. A. Bagheri, J. Jin, ACS Appl. Polymer. Mater. 1(4), 593-611 (2019). https://doi.org/10.1021/acsapm.8b00165

30. S. Joshi, K. Rawat, C. Karunakaran, V. Rajamohan, A.T. Mathew, K. Koziol, V.K. Thakur, A.S.S. Balan, 4D printing of materials for the future: opportunities and challenges. Appl. Mater. Today, 100490 (2019). https://doi.org/10.1016/j.apmt.2019.100490

31. M. Guvendiren, J. Molde, R.M.D. Soares, J. Kohn, Designing biomaterials for 3D printing. ACS Biomater. Sci. Eng. 2, 1679 1693 (2016). https://doi.org/10.1021/acsbiomaterials.6b00121

32. K.M. Park, S. Gerecht, Polymeric hydrogels as artificial extracellular microenvironments for cancer research. Eur. Polym. J. 72, 507-513 (2015). https://doi.org/10.1016/j.eurpolymj.2015.06.030

33. F. Obregon, C. Vaquette, S. Ivanovski, D.W. Hutmacher, L.E. Bertassoni, Three-dimensional bioprinting for regenerative dentistry and craniofacial tissue engineering. J. Dent. Res. 94, 143S-152S (2015). https://doi.org/10.1177/0022034515588885

34. J. Leor, Y. Amsalem, S. Cohen, Cells, scaffolds, and molecules for myocardial tissue engineering. Pharmacol. Ther. 105, 151-163 (2005). https://doi.org/10.1016/j.pharmthera.2004.10.003

35. U. Jammalamadaka, K. Tappa, Recent advances in biomaterials for $3 \mathrm{D}$ printing and tissue engineering. J. Funct. Biomater 9, 22 (2018). https://doi.org/10.3390/jfb9010022

36. H.T. Aiyelabegan, S.S.Z. Zaidi, S. Fanuel, A. Eatemadi, M.T.K. Ebadi, E. Sadroddiny, Albumin-based biomaterial for lung tissue engineering applications. Int. J. Polym. Mater. Polym. Biomater. 65, 853-861 (2016) 
37. D. Wang, B. Hu, C. Hu, F. Zhu, X. Liu, J. Zhang, B. Wang, H. Xiang, Z. Cheng, Y. Xiong, Y. Zhao, Y. Li, X. Wang, Z. Peng, Clinical characteristics of 138 hospitalized patients with 2019 novel coronavirus-infected pneumonia in Wuhan, China. Jama 323, 1031-1069 (2020). https://doi.org/10.1001/jama.2020.1585

38. Z. Xu, L. Shi, Y. Wang, J. Zhang, L. Huang, C. Zhang, F.-S. Wang, Pathological findings of COVID-19 associated with acute respiratory distress syndrome. Lancet Respir. Med. 8, 420-422 (2020). https://doi.org/10.1016/s2213-2600(20)30076-x

39. J. Goole, K. Amighi, 3D printing in pharmaceutics: a new tool for designing customized drug delivery systems. Int. J. Pharm. 499, 376-394 (2016). https://doi.org/10.1016/j.ijpharm.2015.12.071

40. H. He, M. Gao, B. Illés, K. Molnar, 3D printed and electrospun, transparent, hierarchical polylactic acid mask nanoporous filter. Int. J. Bioprint. 6, 4 (2020). https://doi.org/10.18063/ijb.v6i4.278

41. M.M. Erickson, E.S. Richardson, N.M. Hernandez, D.W. Bobbert, K. Gall, P. Fearis, Helmet modification to PPE with 3D printing during the COVID-19 pandemic at Duke University Medical Center: a novel technique. J. Arthroplast. 35, S23-S27 (2020). https://doi.org/10.1016/j.arth.2020.04.035

42. Y.Y.C. Choong, H.W. Tan, D.C. Patel, W.T.N. Choong, C.-H. Chen, H.Y. Low, C.K. Chua, The global rise of 3D printing during the COVID-19 pandemic. Nat. Rev. Mater. 5, 637-639 (2020). https://doi.org/10.1038/s41578-020-00234-3

43. C.J. Callahan, R. Lee, K.E. Zulauf, L. Tamburello, K.P. Smith, J. Previtera, R.A. Arnaout, Open development and clinical validation of multiple 3D-printed nasopharyngeal collection swabs: rapid resolution of a critical COVID-19 testing bottleneck. J. Clin. Microbiol. 58, e00876 (2020). https://doi.org/10.1128/jcm.0087620

44. H.K. Celik, O. Kose, M.-E. Ulmeanu, A.E.W. Rennie, T.N. Abram, I. Akinci, Design and additive manufacturing of a medical face shield for healthcare workers battling coronavirus (COVID19). Int. J. Bioprint. 6, 286 (2020). https://doi.org/10.18063/ijb. v6i4.286

45. A.M. Armani, D.E. Hurt, D. Hwang, M.C. McCarthy, A. Scholtz, Low-tech solutions for the COVID-19 supply chain crisis. Nat. Rev. Mater. 5, 403-406 (2020). https://doi.org/10.1038/s41578020-0205-1

46. D. Sher, Leitat presents first medically validated, industrialized 3D printed emergency respiration device, https://www. 3 dprintingmedia.network/leitat-presents-first-medicallyvalidated-industrialized-3d-printed-ventilator/. Accessed 7 September 2020

47. N. Vordos et al., How $3 \mathrm{D}$ printing and social media tackles the PPE shortage during Covid-19 pandemic. Saf. Sci., 104870 (2020). https://doi.org/10.1016/j.ssci.2020.104870

48. M. Tarfaoui, M. Nachtane, I. Goda, Y. Qureshi, H. Benyahia, 3D printing to support the shortage in personal protective equipment caused by COVID-19 pandemic. Materials 13(15), 3339 (2020). https://doi.org/10.3390/ma13153339

49. Cummin Filtration, https://fastlifehacks.com/n95-vs-ffp/ Accessed 22 August 2020

50. C.N. Thomas, L.K. Schroder, P.A. Cole, Ten days to implementation of 3D-printed masks for a level-I orthopaedic trauma practice during the COVID-19 pandemic. J. Bone Joint Surg. 102, e95 (2020). https://doi.org/10.2106/JBJS.20.00881

51. Copper 3D, antimicrobial $3 \mathrm{~d}$ printing and active materials, https:// copper3d.com/. Accessed 23 August 2020

52. D. Kvaternik, HEPA Covid coronavirus face mask (2020), https:// www.thingiverse.com/thing:4222563. Accessed 23 August 2020

53. R. Tino, R. Moore, S. Antoline, P. Ravi, N. Wake, C.N. Ionita, J.M. Morris, S.J. Decker, A. Sheikh, F.J. Rybicki, L.L. Chepelev, COVID-19 and the role of 3D printing in medicine. 3D Print. Med. 6, 11 (2020). https://doi.org/10.1186/s41205-020-00064-7
54. Lowell makes, 3D-printed masks, https://lowellmakes.com/3dprinted-masks/. Accessed 30 August 2020

55. J. Alexander, N95 vs FFP3\&FFP2 masks - What's the difference? https://fastlifehacks.com/n95-vs-ffp/. Accessed 20 August 2020

56. H. Agarwal, A. Jain, K. Goyal, G. Sumiran, Self-designed 3-D printed mask to tackle COVID-19. Glob. J. Res. Eng. 20, 57-65 (2020)

57. S.T. Flanagan, D.H. Ballard, 3D printed face shields: a community response to the COVID-19 global pandemic. Acad. Radiol. 27, 905-906 (2020). https://doi.org/10.1016/j.acra.2020.04.020

58. D. Amin, N. Nguyen, S.M. Roser, S. Abramowicz, 3D printing of face shields during COVID-19 pandemic: a technical note. Oral Maxillofac. Surg. 78, 1275-1278 (2020). https://doi.org/10.1016/ j.joms.2020.04.040

59. L. Cavallo, A. Marcianò, M. Cicciù, G. Oteri, 3D printing beyond dentistry during COVID 19 epidemic: a technical note for producing connectors to breathing devices. Prosthesis 2(2), 46-52 (2020). https://doi.org/10.3390/prosthesis2020005

60. G.R.J. Swennen, L. Pottel, P.E. Haers, Custom-made 3D-printed face masks in case of pandemic crisis situations with a lack of commercially available FFP2/3 masks. Int. J. Oral Maxillofac. Surg. 49, 673-677 (2020). https://doi.org/10.1016/j.ijom.2020. 03.015

61. J. Rojo, A. Sousa-Herves, A. Mascaraque, 1.24 - Perspectives of carbohydrates in drug discovery. Comprehen. Med. Chem. III, 577-610 (2017). https://doi.org/10.1016/B978-0-12-409547-2. 12311-X

62. S. Ishack, S.R. Lipner, Applications of 3D printing technology to address COVID-19-related supply shortages. Am. J. Med. 133, 771-773 (2020). https://doi.org/10.1016/j.amjmed.2020.04.002

63. T. Mueller, A. Elkaseer, A. Charles, J. Fauth, D. Rabsch, A. Scholz, C. Marquardt, K. Nau, S.G. Scholz, Eight weeks laterthe unprecedented rise of 3D printing during the COVID-19 pandemic - a case study, lessons learned, and implications on the future of global decentralized manufacturing. Appl. Sci. 10, 4135 (2020). https://doi.org/10.3390/app10124135

64. A. Manero, P. Smith, A. Koontz, M. Dombrowski, J. Sparkman, D. Courbin, A. Chi, Leveraging 3D printing capacity in times of crisis: recommendations for COVID-19 distributed manufacturing for medical equipment rapid response. Int. J. Environ. Res. Public Health 17, 4634 (2020). https://doi.org/10.3390/ijerph17134634

65. J. Hadaya, M. Schumm, E.H. Livingston, Testing individuals for coronavirus disease 2019 (COVID-19). JAMA 323, 1981 (2020)

66. Centers for Disease Control and Prevention, Specimen collection, interim guidelines for collecting, handling, and testing clinical specimens from persons for coronavirus disease 2019 (COVID19) https:/www.cdc.gov/coronavirus/2019-nCoV/lab/guidelinesclinical-specimens.html. Accessed 20.09.2020

67. Z. Starosolski, P. Admane, J. Dunn, B. Kaziny, T. Huisman, A. Annapragada, Design of 3D-printed nasopharyngeal swabs for children is enabled by radiologic imaging. Am. J. Neuroradiol. (2020). https://doi.org/10.3174/ajnr.a6794

68. J. Cox, S. Koepsell, 3D-printing to address COVID-19 testing supply shortages. Lab. Med. 51, e45-e46 (2020). https://doi.org/ 10.1093/labmed/lmaa031

69. E. Williams, K. Bond, N. Isles, B. Chong, D. Johnson, J. Druce, T. Hoang, S.A. Ballard, V. Hall, S. Muhi, K.L. Buising, S. Lim, D. Strugnell, M. Catton, L.B. Irving, B.P. Howden, E. Bert, D.A. Williamson, Pandemic printing: a novel 3D-printed swab for detecting SARS-CoV-2. Med. J. Aust. 213, 276-279 (2020). https:// doi.org/10.5694/mja2.50726

70. J. Ford, T. Goldstein, S. Trahan, A. Neuwirth, K. Tatoris, S. Decker, A 3D-printed nasopharyngeal swab for COVID-19 diagnostic testing. 3D Print. Med. 6 (2020). https://doi.org/10.1186/ s41205-020-00076-3 
71. N. Gallup, A. Pringle, S. Oberloier, N. Tanikella, J. Pearce, Parametric nasopharyngeal swab for sampling COVID-19 and other respiratory viruses: open source design, SLA 3-D printing and UV curing system. HardwareX 8, e00135 (2020). https://doi. org/10.1016/j.ohx.2020.e00135

72. T. Boissonneault, These 3D printed nasal swabs self-adjust for comfort. 3D Print. Media Netw. (2020) https://www. 3 dprintingmedia.network/3d-printed-nasal-swabs-self-adjust/ Accessed 18 September 2020

73. S. Ayyıldız, A. Dursun, V. Yıldırım, M. İnce, M. Gülçelik, C. Erdöl, 3D-printed splitter for use of a single ventilator on multiple patients during COVID-19. 3D Print. Addit. Manuf. 7, 181-185 (2020). https://doi.org/10.1089/3dp.2020.0102

74. K. Iyengar, S. Bahl, R. Vaishya, A. Vaish, Challenges and solutions in meeting up the urgent requirement of ventilators for COVID-19 patients. Diabetes Metab. Syndr. Clin. Res. Rev. 14, 499-501 (2020). https://doi.org/10.1016/j.dsx.2020.04.048

75. S. Belhouideg, Impact of $3 \mathrm{D}$ printed medical equipment on the management of the Covid19 pandemic. Int. J. Health Plann. Manag. (2020). https://doi.org/10.1002/hpm.3009

76. A. Faryami, C. Harris, Open source 3D printed ventilation device (2020). https://doi.org/10.1101/2020.05.21.108043

77. A. Caldwell, UC San Diego engineers and doctors team up to retrofit and 3-D print ventilators. UC San Diego News (2020). https://www.universityofcalifornia.edu/news/uc-san-diegoengineers-and-doctors-team-retrofit-and-3d-print-ventilators. Accessed 19.09.2020

78. Businesswire, Northwell Health converts BiPAP machines into ventilators for hospitalized COVID-19 patients, uses 3D printed adapter (2020). https://www.businesswire.com/news/home/ 20200331005506/en/Northwell-Health-Converts-BiPAPMachines-Into-Ventilators-for-Hospitalized-COVID-19-PatientsUses-3D-Printed-Adapter Accesed 19 September 2020

79. Northwell Health, Northwell Health converts BiPAP machines into ventilators for hospitalized COVID-19 patients, uses 3D printed adapter https://feinstein.northwell.edu/news/the-latest/ northwell-converts-bipap-machines-into-ventilators-forhospitalized-covid-19-patients-uses-3d-printed-adapter Accesed 19 September 2020

80. B. de Vet, 3D-printed non-invasive PEEP masks aim to alleviate ventilator shortage. Materialise (2020) https://www.materialise. $\mathrm{com} / \mathrm{en} / \mathrm{blog} / 3 \mathrm{~d}$-printed-peep-mask-alleviate-ventilator-shortage Accessed 19 September 2020

81. A. Clarke, 3D printed circuit splitter and flow restriction devices for multiple patient lung ventilation using one anaesthesia workstation or ventilator. Anaesthesia 75, 819-820 (2020). https://doi. org/10.1111/anae. 15063

82. S.C. Greenville, Innovative ventilator device developed by Prisma Health to quickly increase ventilator capacity for COVID-19 patients. Prisma Health (2020) https://www.ghs.org/healthcenter/ ghsblog/prisma-health-ventilator-covid19/. Accessed 19 September 2020

83. Z. Kleinman, Coronavirus: $3 \mathrm{D}$ printers save hospital with valves. BBC News (2020). https://www.bbc.com/news/technology51911070 Accesed 19 September 2020

84. K. Stevenson, Photocentric's high-volume approach to ventilator valve production, Fabbaloo 3D PRINTING NEWs (2020) https:// www.fabbaloo.com/blog/2020/3/23/photocentrics-high-volumeapproach-to-ventilator-valve-production. Accessed 19 September 2020

85. CRP Technology, CRP Technology on the front line in the fight against Covid-19, https://www.crptechnology.com/front-linefight-against-covid19-mask-3d-printing/ Accessed 19 September 2020

86. N. Flaherty, 3D printing emergency valves for ventilators, eeNews EUROPE (2020). https://www.eenewseurope.com/news/3d- printing-emergency-valves-ventilators Accessed 19 September 2020

87. D. Sher, Ferrari joins 3D printing effort to fight the COVID-19 pandemic, https://www.3dprintingmedia.network/ferrari-joins3d-printing-effort-to-fight-the-covid-19-pandemic/ Accessed 19 September 2020

88. Axial 3D, Axial3D gives a world-first insight into the lungs of a COVID-19 patient with 3D printing, https://www.axial3d.com/ blog/axial3d-gives-a-world-first-insight-into-the-lungs-of-acovid-19-patient-with-3d-printing/ Accessed 19 September 2020

89. M. Jacob, E. Ruivo, I. Portelai, J. Tavares, M. Varela, S. Moutinho, H. Costa, D. Nunez, An innovative endotracheal tube clamp for use in COVID-19. Can. J. Aesthesia 67, 1468-1470 (2020). https://doi.org/10.1007/s12630-020-01703-7

90. P.M. François, X. Bonnet, J. Koisor, J. Adam, R.H. Khonsari, 3Dprinted contact-free devices designed and dispatched against the COVID-19 pandemic: the 3D COVID initiative. J Stomatol Ora Maxillofac Surg, In Press (2020). https://doi.org/10.1016/j.jormas. 2020.06.010

91. Materialise, Hands-free door openers technical information, https://www.materialise.com/en/hands-free-door-opener/ technical-information Accessed 30 August 2020

92. T. Boissonneault, Belfast doctors study COVID-19 effects with 3D printed lung model. 3D Print. Media Netw. (2020) https:// www.3dprintingmedia.network/belfast-long-term-covid-19-lungmodel-3d/ Accessed 19 September 2020

93. D. Sher, WinSun/Yingchuang ships 15 3D printed isolation wards to Pakistan to fight COVID-19, (2020). https://www. 3 dprintingmedia.network/winsun-yingchuang-ships-15-3dprinted-isolation-wards-to-pakistan-to-fight-covid-19/ Accesed 19 September 2020

94. E. Gonzalez-Gonzalez, I.M. Lara-Mayorga, I.P. RodriguezSanchez, F. Yee-de Leon, A. Garcia-Rubio, C.E. GarciamendezMijares, G.E. Guerra-Alvarezi G. Garcia-Martinez, J.A. AguayoHernandez, E. Marquez-Garcia, Y-S. Zhang, S.O. MartinezChapa, J. Zuniga, G. Trujillo-de Santiago, M.M. Alvarez, Scaling diagnostics in times of COVID-19: colorimetric loopmediated isothermal amplification (LAMP) assisted by a 3Dprinted incubator for cost-effective and scalable detection of SARS-CoV-2 (2020). https://doi.org/10.1101/2020.04.09. 20058651

95. M. Petch, 3d printing community responds to Covid-19 and coronavirus resources, 3D Printing Industry (2020) https:// 3 dprintingindustry.com/news/3d-printing-community-respondsto-covid-19-and-coronavirus-resources-169143/ Accessed 20 September 2020

96. S. Singh, C. Prakash, S. Ramakrishna, Three-dimensional printing in the fight against novel virus COVID-19: technology helping society during an infectious disease pandemic. Technol. Soc. 62, 101305 (2020). https://doi.org/10.1016/j.techsoc.2020.101305

97. E.A. Calle, T.H. Petersen, L.E. Niklason, Procedure for lung engineering. J. Vis. Exp. 49 (2011). https://doi.org/10.3791/2651

98. W. Chrzanowski, S.Y. Kim, L. Mcclements, Can stem cells beat COVID-19: advancing stem cells and extracellular vesicles towards mainstream medicine for lung injuries associated with SARS-CoV-2 infections. Front. Bioeng. Biotechnol. 8, 554 (2020). https://doi.org/10.3389/fbioe.2020.00554

99. P. Macchiarini, P. Jungebluth, T. Go, M.A. Asnaghi, L.E. Rees, T.A. Cogan, M.A. Birchall, Clinical transplantation of a tissueengineered airway. Lancet 372, 2023-2030 (2008). https://doi. org/10.1016/s0140-6736(08)61598-6

100. J.E. Nichols, J. Niles, M. Riddle, G. Vargas, T. Schilagard, L. Ma, J. Cortiella, Production and assessment of decellularized pig and human lung scaffolds. Tissue Eng. A 19, 2045-2062 (2013). https://doi.org/10.1089/ten.tea.2012.0250 
101. T. Takebe, K. Sekine, M. Enomura, H. Koike, M. Kimura, T. Ogaeri, R.-R. Zhang, Y. Ueno, Y.-W. Zheng, N. Koike, S. Aoyama, Y. Adachi, H. Taniguchi, Vascularized and functional human liver from an iPSC-derived organ bud transplant. Nature 499, 481-484 (2013). https://doi.org/10.1038/nature12271

102. M. Nishiga, D.W. Wang, Y. Han, D.B. Lewis, J.C. Wu, COVID19 and cardiovascular disease: from basic mechanisms to clinical perspectives (2020). https://doi.org/10.1038/s41569-020-0413-9

103. M.R. Melhem, J. Park, L. Knapp, L. Reinkensmeyer, C. Cvetkovic, J. Flewellyn, et al., 3D Printed stem-cell-laden, microchanneled hydrogel patch for the enhanced release of cellsecreting factors and treatment of myocardial infarctions. ACS Biomater. Sci. Eng. 3(9), 1980-1987 (2016). https://doi.org/10. 1021/acsbiomaterials.6b00176

104. Y. Zhang, X. Geng, Y. Tan, Q. Li, C. Xu, J. Xu, L. Hao, Z. Zeng, X. Luo, F. Liu, H. Wang, New understanding of the damage of SARS-CoV-2 infection outside the respiratory system. Biomed. Pharmacother. 127, 110195 (2020). https://doi.org/10.1016/j. biopha.2020.110195

105. F.G. De Felice, F. Tovar-Moll, J. Moll, D.P. Munoz, S.T. Ferreira, Severe acute respiratory syndrome coronavirus 2 (SARS-CoV-2) and the central nervous system. Trends. Neurosci. 43(6), 355-357 (2020). https://doi.org/10.1016/j.tins.2020.04.004

106. D. Joung, N.S. Lavoie, S.Z. Guo, S.H. Park, A.M. Parr, M.C. McAlpine, 3D printed neural regeneration devices. Adv. Funct. Mater. 30(1) (2020). https://doi.org/10.1002/adfm.201906237

107. R. Lozano, L. Stevens, B.C. Thompson, K.J. Gilmore, R. Gorkin, E.M. Stewart, M. Panhuis, M. Romero-Ortega, G.G. Wallace, 3D printing of layered brain-like structures using peptide modified gellan gum substrates. Biomaterials 67, 264-273 (2015). https:// doi.org/10.1016/j.biomaterials.2015.07.022

108. S.J. Lee, W. Zhu, M. Nowicki, G. Lee, D.N. Heo, J. Kim, Y. Y, L.G.Z. Zuo, 3D printing nano conductive multi-walled carbon nanotube scaffolds for nerve regeneration. J. Neural Eng. 15(1), 016018 (2018). https://doi.org/10.1088/1741-2552/aa95a5

109. X. Zhou, H. Cui, M. Nowicki, S. Miao, S.J. Lee, F. Masood, B.T. Harris, L.G. Zhang, Three-dimensional-bioprinted dopaminebased matrix for promoting neural regeneration. ACS Appl. Mater. Interfaces 10(10), 8993-9001 (2018). https://doi.org/10. 1021/acsami.7b18197

110. Y.-Y. Deng, Y. Zheng, G.-Y. Cai, X.-M. Chen, Q. Hong, Singlecell RNA sequencing data suggest a role for angiotensinconverting enzyme 2 in kidney impairment in patients infected with 2019-novel coronavirus. Chin. Med. J. 133, 1129-1131 (2020). https://doi.org/10.1097/CM9.0000000000000783

111. S. Naicker, C.-W. Yang, S.-J. Hwang, B.-C. Liu, J.-H. Chen, V. Jha, The novel coronavirus 2019 epidemic and kidneys. Kidney Int. 97, 824-828 (2020). https://doi.org/10.1016/j.kint.2020.03. 001

112. F. Adams, T. Qiu, A. Mark, B. Fritz, L. Kramer, D. Schlager, U. Wetterauer, A. Miernik, P. Fischer, Soft 3D-printed phantom of the human kidney with collecting system. Ann. Biomed. Eng., 45963-972 (2016). https://doi.org/10.1007/s10439-016-1757-5

113. M. Kusaka, M. Sugimoto, N. Fukami, H. Sasaki, M. Takenaka, T. Anraku, T. Ito, T. Kenmochi, R. Shiroki, K. Hoshinaga, Initial experience with a tailor-made simulation and navigation program using a 3-D printer model of kidney transplantation surgery. Transplant. Proc. 47, 596-599 (2015). https://doi.org/10.1016/j. transproceed.2014.12.045
114. S.M. King, O.A. Creasey, S.C. Presnell, D.G. Nguyen, Design and characterization of a multicellular, three-dimensional (3D) tissue model of the human kidney proximal tubule (Organovo, Inc.)

115. C. Baraniuk, Receptors for SARS-CoV-2 present in wide variety of human cells. The Scientist, https://www.the-scientist.com/ news-opinion/receptors-for-sars-cov-2-present-in-wide-varietyof-human-cells-67496. Accessed on 13 September 2020

116. A. Atala, Tissue engineering of human bladder. Br. Med. Bull. (March). https://doi.org/10.1093/bmb/ldr003

117. B. Lord, Bladder grown from 3D bioprinted tissue continues to function after 14 years, https://3dprintingindustry.com/news/ bladder-grown-from-3d-bioprinted-tissue-continues-to-functionafter-14-years-139631/ Accessed on 30 September 2020

118. J. Segars, Q. Katler, D.B. McQueen, A. Kotlyar, T. Glenn, Z. Knight, E.C. Feinberg, H.S. Taylor, J.P. Toner, J.F. Kawwass, ASRM Coronavirus/COVID-19 Task Force, prior and novel coronaviruses, COVID-19, and human reproduction: what is known? Fertil. Steril. 113, 1140-1149 (2020). https://doi.org/10. 1016/j.fertnstert.2020.04.025

119. I. Sfontouris, Assisted reproduction treatment during the Covid-19 pandemic: considerations based on ovarian physiology. www. fertstertdialog.com/rooms/871-covid-19/conversations/15418. Accessed on 13 September 2020

120. M.E. Zubizarreta, S. Xiao, Bioengineering models of female reproduction. Bio-Des. Manufact. 3, 237-251 (2020). https://doi. org/10.1007/s42242-020-00082-8

121. A.M. Raya-Rivera, C. Baez, A. Atala, J.J. Yoo, Tissue engineered testicular prostheses with prolonged testosterone release. World J. Urol. 26, 351-358 (2008). https://doi.org/10.1007/s00345-0080267-y

122. Y. Wen, S. Xun, M. Haoye, S. Baichuan, C. Peng, L. Xuejian, Z. Kaihong, Y. Xuan, P. Jiang, L. Shibi, 3D printed porous ceramic scaffolds for bone tissue engineering: a review. Biomater. Sci. 5, 1690-1698 (2017). https://doi.org/10.1039/c7bm00315c

123. Ž.P. Kačarević, P.M. Rider, S. Alkildani, S. Retnasingh, R. Smeets, Q. Jung, M. Barbeck, An introduction to 3D bioprinting: possibilities, challenges and future aspects. Materials 11, 2199 (2018). https://doi.org/10.3390/ma11112199

124. W. Jamróz, J. Szafraniec, M. Kurek, R. Jachowicz, 3D Printing in pharmaceutical and medical applications - recent achievements and challenges. Pharm. Res. 35, 176 (2018). https://doi.org/10. 1007/s11095-018-2454-x

125. N. Travitzky, A. Bonet, B. Dermeik, T. Fey, I. Filbert-Demut, L. Schlier, T. Schlordt, P. Greil, Additive manufacturing of ceramicbased materials. Adv. Eng. Mater. 16, 729-754 (2014). https://doi. org/10.1002/adem.201400097

126. C. Di Bella, S. Duchi, C.D. O'Connell, R. Blanchard, C. Augustine, Z. Yue, P.F. Choong, In situ handheld threedimensional bioprinting for cartilage regeneration. J. Tissue Eng. Regen. Med. 12, 611-621 (2018). https://doi.org/10.1002/ term. 2476

127. T. Xu, K. Binder, M. Albanna, D. Dice, W. Zhao, J. Yoo, A. Atala, Hybrid printing of mechanically and biologically improved constructs for cartilage tissue engineering applications. Biofabrication 5, 015001 (2013). https://doi.org/10.1088/1758$5082 / 5 / 1 / 015001$ 